\title{
Personality and Suicidal Behavior in Old Age: A Systematic Literature Review
}

\author{
Anna Szücs ${ }^{1,2 *}$, Katalin Szanto², Jean-Michel Aubry ${ }^{1}$ and Alexandre Y. Dombrovski² \\ ${ }^{1}$ Department of Psychiatry, Faculty of Medicine, University of Geneva, Geneva, Switzerland, ${ }^{2}$ Decision Neuroscience \\ and Psychopathology Laboratory, Department of Psychiatry, School of Medicine, University of Pittsburgh, Pittsburgh, PA, \\ United States
}

Background: Suicide rates generally peak in the second half of life and are particularly high in older men; however, little is known about the contribution of dispositional factors to late-life suicide. Maladaptive personality traits have been strongly implicated in suicide among younger adults, but the extent to which they continue to play a role in late-life suicidal behavior is unclear. We also do not know whether specific personality profiles interact with the stressors of aging to cause suicidal behavior.

Methods: We sought to synthesize the data on personality pathology in late-life suicidal ideation and behavior via a systematic review using the PubMed, Google Scholar, Psyclnfo, Scopus, Ovid, Web of Science, Embase, and Cochrane search engines. The

OPEN ACCESS

Edited by:

Yari Givion,

Bar-llan University, Israel

Reviewed by:

Katie Moraes de Almondes,

Federal University of Rio

Grande do Norte, Brazil

Serge Brand,

Universität Basel, Switzerland

${ }^{*}$ Correspondence:

Anna Szücs

anna.szuecs@etu.unige.ch, szuecs.anna@gmail.com

Specialty section:

This article was submitted

to Psychopathology,

a section of the journal

Frontiers in Psychiatry

Received: 30 November 2017

Accepted: 26 March 2018

Published: 07 May 2018

Citation:

Szücs A, Szanto K, Aubry J-M and Dombrovski AY (2018) Personality and Suicidal Behavior in Old Age:

A Systematic Literature Review.

Front. Psychiatry 9:128.

doi: 10.3389/fpsyt.2018.00128 included key words related to three descriptors: "personality," "suicide," and "elderly." Included articles evaluated personality based on the Five-Factor Model (FFM) or ICD/ DSM diagnostic criteria in older samples with minimum age cutoffs of 50 years or older. Our original search identified 1,183 articles, of which 31 were retained.

Results: Included studies were heterogeneous in their design and personality measurements. Studies of categorical personality disorders were particularly scarce and suggested a stronger association with late-life suicidal ideation than with death by suicide. Only obsessive-compulsive and avoidant personality traits were associated with death by suicide in old age, but only in studies that did not control for depression. All personality constructs were positively linked to suicidal ideation, except for histrionic personality, which emerged as a negative predictor. Studies employing the FFM also indicated that older adults who died by suicide were less likely to display a maladaptive personality profile than elderly suicide attempters and younger suicide victims, having both lower levels of neuroticism and higher levels of conscientiousness than these comparison groups. Nevertheless, older suicide victims displayed lower levels of openness to experience than younger victims in two samples.

Conclusion: Maladaptive personality manifests in milder, subthreshold, and more heterogeneous forms in late-life vs. early-life suicide. An inability to adapt to the changes occurring in late life may help explain the association between suicide in old age and higher conscientiousness as well as obsessive-compulsive and avoidant personality disorders.

Keywords: aged, elderly, suicide, attempted suicide, suicidal ideation, personality, personality disorder, Five-Factor Model 


\section{INTRODUCTION}

\section{Rationale}

There has been a continuous rise in suicide rates in the United States, increasing from 10.5 to 13 per 100,000 between 1999 and 2014 (1). Suicide rates peak after age 45 for both males and females, with the highest rates in the population found in older white men aged 85 or older, for whom rates are as high as 50.7 per 100,000 (2). The known risk factors for suicide in old age remain largely unspecific, however, giving us only a limited understanding of the psychological mechanisms involved. For example, depression, physical decline, family discord, social isolation, and financial issues are well-established risk factors for suicide (3-6), but they are also present in many older adults who never engage in suicidal behavior. According to the stressdiathesis model, suicidal individuals may possess lifelong traits of vulnerability, and it is the interaction between such traits and acute stressors that triggers suicidal behavior (7). Maladaptive personality traits are strongly implicated both with suicide among younger adults and with failure to cope with the stressors of aging (8-10). Thus, the stress-diathesis framework informs two questions. First, to what extent do the personality features implicated in suicide among younger adults confer suicide risk in old age? Second, what personality profiles are uniquely associated with late-life suicide by virtue of their interaction with the stressors of aging (e.g., physical decline)? We can even entertain the possibility of pleiotropic effects $(11,12)$ wherein traits that confer a reproductive advantage earlier in life could increase suicide risk in old age. To the best of our knowledge, in the existing literature, there is no consensus on these questions.

On the other hand, an association between personality disorders and suicidal behavior has been reported in most studies examining younger adults $(13,14)$. All personality disorders, with the exception of schizoid and histrionic, are associated with increased suicide risk in clinical or community-dwelling adult samples (14-18). Studies using dimensional models of personality also link both suicide attempts and death by suicide with high neuroticism and low extraversion, two traits that are also correlated with depression and broadly defined psychopathology (19-23). Borderline personality disorder (BPD) has been most strongly implicated in adult suicidal behavior, being linked to multiple attempts starting at an earlier age, and often mediated by impulsivity $(14,24,25)$. However, externalizing aspects of BPD and impulsive traits specifically are most severe in young adulthood and tend to subside with age $(26,27)$. Moreover, in contrast to the high-impulsivity, lower-lethality suicidal behavior of younger age groups, the elderly tend to carry out fewer but higher-lethality suicidal acts, characterized by careful planning, and often occurring without warning signs $(28,29)$. These observations suggest that suicidal behavior in old age may be associated with personality profiles that are distinct from borderline and Cluster B pathology.

\section{Objectives}

This study aims to provide a comprehensive overview of the existing literature on the personality profiles of the suicidal elderly. Section "Results" first summarizes the characteristics of the studies, then reports data on personality pathology as a whole, and finally focuses separately on each DSM personality disorder and Five-Factor domain. Although the definition of personality can encompass all individual differences in characteristic patterns of thinking, feeling, and behaving (30), our theoretical focus on categorical personality disorders and the Big Five precluded us from reviewing studies that assessed other trait-like constructs, such as impulsivity or aggression. In this study, we considered behavior to be suicidal if it was self-injurious and enacted with intent to kill oneself, and suicidal ideation as thoughts of taking one's own life (31). These definitions do not include para-suicide or passive death wish. Even though ideation, attempt, and death by suicide are interconnected entities, they do not correspond to entirely identical clinical populations, since the majority of ideators will never attempt suicide (32), and the majority of attempters do not die by suicide (33). Supporting this view, distinct yet partially overlapping personality profiles have been found in adult suicide ideators and attempters (34-36). Thus, this review will address findings on death by suicide, attempted suicide, and suicidal ideation separately in each subsection.

\section{Research Question}

The question we sought to answer is whether elderly who engage in suicidal behavior display qualitatively different personality profiles compared to their younger counterparts. Given the abatement of externalizing behaviors with aging, including BPD symptoms, we hypothesized that the contribution of these traits to suicidal behavior will diminish in old age. Furthermore, we sought to clarify whether differences in personality profiles exist in the elderly between those with ideation exclusively, attempt, and death by suicide. Based on the findings in younger samples mentioned earlier, we expect to see an overall stronger association of dysfunctional personality with suicidal ideation than death by suicide, and moderate levels associated with attempted suicide.

\section{METHODS}

A systematic search was conducted using PubMed, Ovid, Embase, PsycInfo, Cochrane, Web of Science, Scopus, and Google Scholar by cross-referencing three descriptor fields with the following key words (Figure 1): personality (34 key words); suicide (5 key words); and elderly (7 key words). Key words were searched in title and abstract when possible, or else in abstract only (Ovid, PsycInfo), and finally in title only where none of the above were available (Google Scholar, Web of Science). In PubMed, where the added ability to use MeSH terms is available, we complemented our search formula with the following MeSH terms: "Personality/psychology," "Personality Disorders/ psychology," "Human Characteristics," and "Impulsive Behavior" were added to the descriptor personality, "suicide" was added to the descriptor suicide and "aged" to the descriptor elderly. In Embase, search terms were both used as free text and mapped on Emtree terms. Reference tracking was done on all included articles to check for additional publications that met inclusion. The search encompassed all articles published through January 31 , 2017, with no beginning time limit and no restrictions on publication status. Our methodology and inclusion criteria 


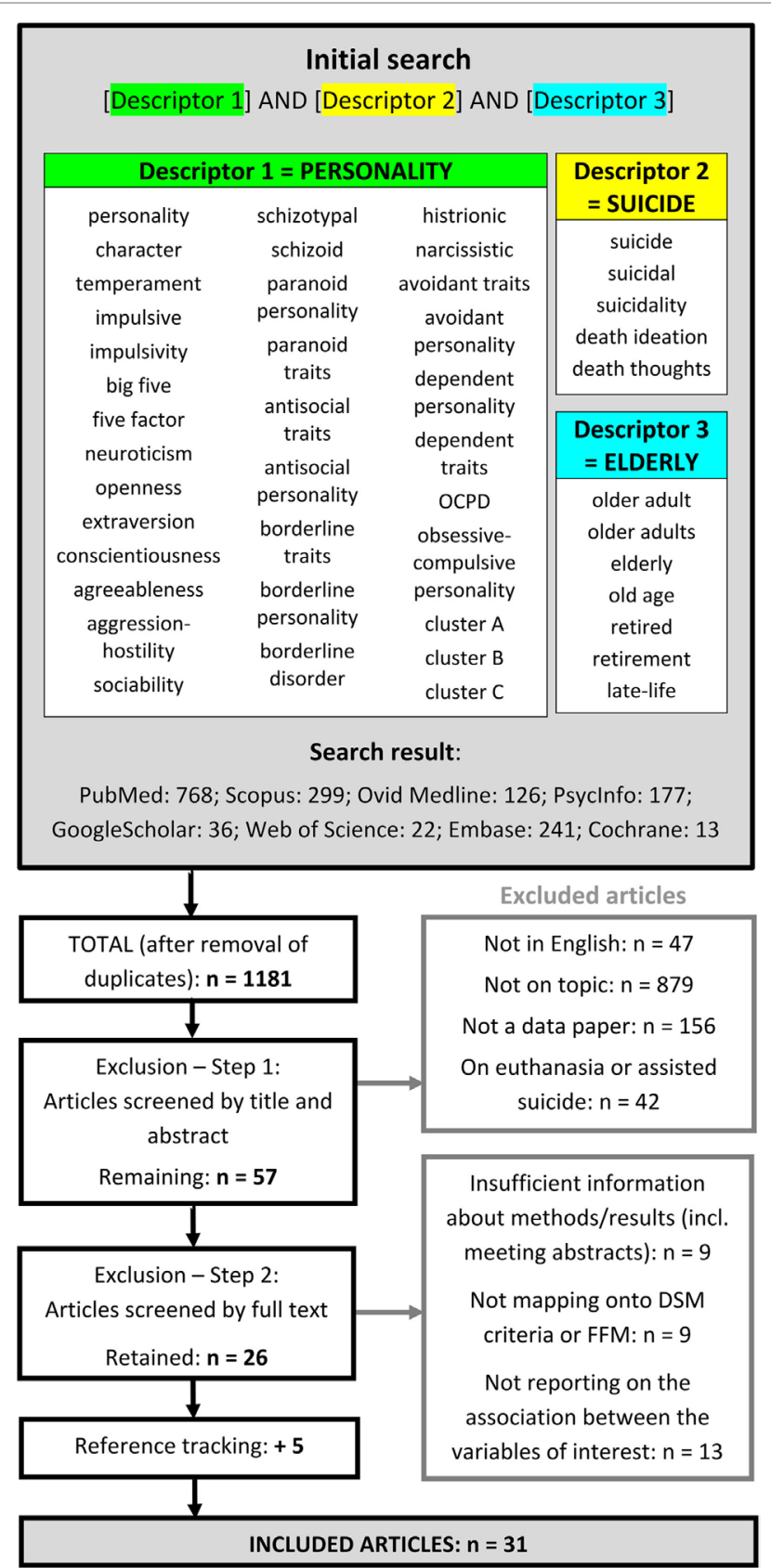

FIGURE 1 | Flow diagram of the studies retrieved for the review. The key words under each descriptor were separated by "OR" for the search. On PubMed, corresponding MeSH terms were added to each descriptor field: Personality, Personality Disorders, Human Characteristics and Impulsive Behavior to Descriptor 1; Suicide to Descriptor 2, and Aged to Descriptor 3. Abbreviation: FFM, Five-Factor Model.

were defined and documented at the beginning of the project. Publications were included if written in English and describing a research study. In addition, articles had to report an assessment of personality specifically, related to any combination of death by suicide, attempted suicide and suicidal ideation. The suicidal behavior/ideation described could not pertain to assisted suicide or euthanasia. Personality had to be assessed via, or map onto the
Five-Factor Model (FFM) or DSM/ICD personality constructs. Studies where personality was not reported separately from other psychiatric diagnoses were excluded, as were all studies not distinguishing between older adults and other age groups, or between suicidal behavior and para-suicide. Older age was defined as equal to or above 50 years. Finally, included articles had to contain sufficient data to evaluate the quality of their findings (e.g., this was not the case for meeting abstracts). In addition to these initial criteria, we later refined the definition of research study to those having a minimum $N$ of 20 to exclude case reports and small qualitative studies oversampling clinically illustrative cases with weakly generalizable data. The first author, AS, performed the initial screening and then reviewed eligibility of potentially includable articles with $\mathrm{AD}$ based on their full text. Of the 1,181 articles found, 1,124 were excluded during the initial screening for one of the following reasons: not written in English (47 articles), not on topic (including all articles about para-suicide/ deliberate self-harm; 879 articles), not a data paper (156 articles), having a euthanasia/assisted suicide focus (42 articles). From the 57 remaining articles, further 31 were excluded based on their full text, either because they contained an insufficient amount of information about methods or results (9 articles), were not mapping onto DSM or FFM personality constructs (9 articles), or were not reporting on the association between personality and suicidal behavior/ideation in the elderly (13 articles). Twenty-six articles were retained for the review, and five more were found by reference tracking.

\section{RESULTS}

\section{Study Characteristics General Characteristics}

Of the 31 included articles (Tables 1-4), one was from 1976 (37), and all others were published after 1990, with seven articles between 1990 and 2000 (38-44), 13 articles between 2001 and 2010 (45-57), and 10 articles between 2011 and 2016 (58-67). The association between personality and either death by suicide, attempted suicide or suicidal ideation was the primary outcome in 18 articles $(39,41,43,45,46,48,50,51$, $53-56,59,61,63,65-67)$, while the other 13 articles reported on personality in relation to a different study focus $(37,38$, $40,42,44,47,49,52,57,58,60,62,64)$. Except for one qualitative study on death by suicide (56) (displayed in Table 2), all studies were quantitative. Five studies followed a purely descriptive design, without control groups (40,42, 50, 52, 56), and only nine of the remaining studies included non-suicidal psychiatric controls $(39,43,44,46-48,51,53,57)$. Seventeen articles reported categorical personality disorder diagnoses (Tables 1-3), and 14 measured dimensional personality traits (Tables 4 and 5), while one article utilized both (displayed in both Tables 2 and 4) (59). Dimensional measures were used in an increasing fraction of articles over time: in 8/21 articles between 1976 and 2010 versus 6/10 from 2011 to 2016 .

\section{Age Cutoffs}

Age cutoffs ranged from 50 to 75 years, with a majority of studies including either participants aged 60 years ( 11 articles) or 65 years 
(12 articles) and older. Only one study had an age cutoff as high as 75 years (61). Mean age was, however, above 70 years in 17/24 articles where these data were available (several studies indicated the percentage of elderly subjects in different age subgroups without reporting a global value for mean age).

\section{Personality Measures}

Even though 17 articles reported on categorical personality disorders, findings about specific personality diagnoses remained scarce in death by suicide and attempted suicide: 6/17 studies reported only global data on personality disorders (38-40, 44, $52,57)$, and two others solely specified BPD in addition to total personality disorders $(42,58)$ (Table 1$)$. Of the remaining nine publications, findings on death by suicide were reported in three articles $(37,45,50)$, two of which were based on the same study (Table 2). No article assessed distinct personality disorders in attempted suicide. Suicidal ideation was assessed by six studies $(47,53,59,65-67)$, of which four were based on the same population (community-dwelling older adults in Colorado, USA) (Table 3). One study on suicidal ideation focused exclusively on narcissistic personality disorder (53).

Of the 14 articles measuring dimensional personality traits (Table 4), two based their findings on the Eysenck Personality Model, assessing only Neuroticism in one case (64), and Neuroticism and Extroversion in the other (61). Based on the reasonable levels of correlation established by Costa and McCrae between Eysenck's Neuroticism and Extroversion and the Five-Factor neuroticism and extraversion domains (68), we considered these constructs equivalent when reporting results. All other studies used the FFM. Most of them exclusively included results for the five main factors, however, 6/14 articles reported findings on the facet level. Subcomponents derived from the NEO-FFI (NEO Five Factor Inventory) such as negative emotions, were interpreted together with the most highly correlated facets derived from the NEO-PI-R (NEO Personality Inventory Revised), in this case, anxiety (69). Three studies with facet-level analyses focused only on specific sets of facets $(46,54$, 62). Overall, five articles provided dimensional data on death by suicide $(41,49,55,60,63)$, seven on attempted suicide $(43,46$, $48,49,55,61,62)$, and six others on suicidal ideation $(43,48,51$, $54,59,64)$. Four articles reported on multiple suicidal outcomes $(43,48,49,55)$. Two articles reported findings based on the same study $(60,63)$. Seven out of the 14 studies based on dimensional models had overlapping samples (elderly patients recruited in the teaching hospitals of the University of Rochester, NY, USA), and two others shared a recruitment source (community-dwelling older adults in Colorado, USA) (Table 4). The dimensional findings, however, came from at least three different sample sources for each suicidal outcome (death, attempt, and ideation).

\section{Definition of Death by Suicide, Attempted Suicide, and Suicidal Ideation}

Not surprisingly, older suicide victims were the most uniformly defined study group, with the obvious inclusion criterion being death by suicide occurring in old age. One study comparing individuals who died by suicide to older attempters also excluded suicide victims with a lifetime history of attempt (55).
While most articles did not define suicide attempt, two studies reportedly used the definition of the World Health Organization $(57,61)$ : “Those situations in which a person has performed a lifethreatening act with the intent of putting his or her life into danger or giving the appearance of such an intent" (70). Other studies defined suicide attempts as any intentional self-destructive act, without necessitating an expressed intent to die, blurring the line between suicide and para-suicide $(40,46,48)$. Most studies used the presence of lifetime attempt history to define their attempters, whereas others necessitated a recent attempt, only including older individuals from either inpatient or emergency units $(38,44,49$, $57,61,62)$. In $4 / 6$ of these cases, history of prior attempts was either controlled for statistically $(49,57)$ or excluded from the control group $(61,62)$.

Some studies included passive death wish in their definition of suicidal ideation $(43,51)$. Further adding to the samples' heterogeneity, studies of elderly suicide ideators neither excluded nor controlled for subjects with past history of suicide attempts. Thus, findings about suicide ideators should be interpreted with caution, since they reflect more a global suicidal risk than pure suicidal contemplation.

\section{Correlates and Possible Mediators Gender}

An established pattern in the literature is that men are more likely to die by suicide while women are more likely to have non-fatal attempts and subsequent mental health contact (71). Thus, a selection bias cannot be excluded in the 14 studies whose suicidal sample was exclusively recruited based on previous contact with psychiatric health services $(37,39,40,43,44,46-49,51-53,55$, $57,61,62)$ as these studies might have oversampled women. While personality pathology increased with late-life suicidal behavior in both genders in most studies, several reported a higher female to male ratio. Lawrence and colleagues found a fivefold higher rate ratio in females with personality pathology than in males for both attempted suicide and death by suicide (44). Qin, whose population study assessed psychiatric illness via the last hospitalization-based principal diagnosis, also reported a threefold higher prevalence of personality pathology in female versus male suicides (58). Not supporting these findings, one case-control study, with separate regression models for elderly male and female attempters, reported that neuroticism was a significant, positive predictor in men but not in women (62). In addition, the Lausanne Study indicated a 1.3 male to female ratio for the prevalence of suicide in former inpatients with personality disorders (37), and Harwood and colleagues' psychological autopsy study did not find a significant gender difference in personality disorder rates (45). The majority of case-control studies included in the review controlled for the potential effect of gender, with only four that did not, or for which this information was missing $(40,47,65,66)$.

\section{Depressive Disorders}

Depressive disorders in old age have been separately associated with both suicidal behavior $(28,72)$, and personality disorders $(9,73)$. Personality disorders co-occur in $10-30 \%$ of depressed elderly, with Cluster $\mathrm{C}$ disorders being the most frequent and 
Cluster B disorders the rarest (9). Patients with personality disorders were found to be up to four times more likely to suffer from the persistence or the re-emergence of depressive symptoms $(39,47)$ and were younger at first onset $(39)$. Morse and Lynch found that the presence and not the severity of personality pathology was correlated with poor prognosis of depressive symptoms in the elderly (47). Of the studies included in this review, only $4 / 12$ studies of death by suicide $(49,55,58,60)$ and $7 / 12$ of suicidal ideation $(43,47,48,51,53,54,65)$ controlled for depression when evaluating the relationship between personality and suicide risk. Studies of attempted suicide were more diligent in this regard, their recruitment source most often being pools of depressed patients. Only one comparative study on attempted suicide lacked any form of adjustment for depressive disorders (44). In 143 older primary care patients, Jahn and colleagues found that depressive symptoms mediated the effect of pathological personality traits on suicidal ideation (65). While none of the studies investigated whether depressive symptoms mediate the effect of personality disorders on suicidal behavior, Nieto and colleagues found that personality disorders occurred independently of all Axis-I diagnoses in 5.2\% of older adults aged 65 or above who made a medically serious suicide attempt $(N=38)(38)$.

\section{Interpersonal Functioning}

Impaired interpersonal functioning is the core feature of personality disorders and a risk factor for suicidal behavior in late-life (74). It is therefore expected to explain the effect of personality pathology on suicidal behavior and ideation. Kunik and colleagues found that depressed inpatients were more likely to be single, separated or divorced if they were diagnosed with a comorbid Axis-II disorder (39). In light of the finding that older adults most often tend to give warning signs about their suicidal intent to their next-of-kin (75), it may be particularly difficult for socially isolated elderly to reach out for help when needed. Conceptualizing the question from the perspective of the interpersonal theory of suicide, Jahn and colleagues identified perceived burdensomeness and thwarted belongingness as mediators between personality disorders and suicidal ideation in older adults aged 65 years or over $(N=143)(65)$. However, Eades found a direct relationship of pathological personality traits and suicidal ideation that was stronger than through either thwarted belongingness or perceived burdensomeness in a community sample of 102 individuals aged 60 or above (67).

\section{Environmental Stressors}

The longitudinal findings of the Lausanne Study suggest higher late-life suicide rates in psychiatric patients who displayed a "specific vulnerability to environmental stress, evident already years ago during their first admission" (37). Harwood and colleagues investigated personality traits in a subsample of individuals who died by suicide and did not have a psychiatric diagnosis $(N=23)$. Their findings indicated that personality trait accentuation was present in $44 \%$ of suicide victims, often concomitantly with recent life events that were thought to have triggered the suicidal act (50). Consistent with Mann's stress-diathesis model of suicide, these findings support the presence of an increased chronic vulnerability that is exacerbated by negative life events in older individuals with already subclinical levels of personality pathology (7).

\section{Synthesized Findings Prevalence of Any Personality Disorder in Late-Life Suicide}

A psychological autopsy by Harwood and colleagues and a retrospective cohort study by Henriksson and colleagues estimated that respectively, 14 and $16 \%$, of adults who died by suicide after the age of 60 had personality disorders $(42,45)$. These rates are somewhat higher than the $10 \%$ community prevalence of personality disorders in adults above 50 years reported by a meta-analysis (76), but the difference remains small considering possible confounding with other psychopathology. Including only principal diagnoses in their analysis, Hunt and colleagues' and Qin's population studies found a much lower prevalence of personality disorders in late-life suicide victims, namely between 1.5 and 5\% $(52,58)$. However, these latter findings are likely less accurate since personality disorders are rarely considered principal diagnoses in this age group (42). Examining personality trait accentuation in addition to personality disorders, Harwood and colleagues' psychological autopsy study found that subthreshold accentuated personality traits were present in $28 \%$ of older adults who died by suicide $(N=100)(45)$. Thus, altogether, $44 \%$ of the suicide victims in Harwood and colleagues' sample had some level of personality pathology.

Despite these relatively high rates of pathological personality disorders and traits in late-life suicide, all studies with younger comparison groups found decreasing prevalence of personality pathology with age $(42,52,57,58)$. The prevalence of any personality disorder was reported to be 2.4 and 2.6 times lower, respectively, in elderly suicide victims aged 60 or above (42), and suicide attempters aged 55 or above (57) than in the younger comparison groups. Both Hunt and colleagues and Harwood and colleagues found that the prevalence of personality disorders further decreased between 60 and 75 years of age in elderly suicide victims (respectively, from 4.0 to $2.3 \%$ for personality disorders as primary diagnoses and from 19.7 to $10.6 \%$ at any detectable level) $(45,52)$.

This significant decrease in older people may be due to the attenuation of symptoms of certain commonly diagnosed personality disorders such as BPD, and/or to a survival bias related to increased premature mortality due to personality pathology. Furthermore, a detection bias is likely in old age given that personality disorders may be masked by overlapping cognitive deficits in a subset of older patients seeking psychiatric care (77). In turn, suicidal behavior may also be under-detected in old age: studies highlighted a decreased number of psychiatric hospitalizations of older adults, both before dying by suicide (58), and after a suicide attempt (44). This may be in part related to diagnostic biases. Indeed, comorbid cognitive deficits, delirium or other organic conditions often lead to medical rather than psychiatric hospitalizations in the elderly with decompensated psychopathology (78); primary health care providers have been found less likely to assess psychopathology in older adults than in younger patients (79); suicidal and death ideation are perceived as part of normal aging by many clinicians (80); and social isolation can cause low-lethality suicide attempts to go unnoticed. 


\section{Association of Personality Disorder Diagnosis With Suicidal Behavior and Ideation in the Elderly Death by Suicide}

A positive correlation between personality pathology and death by suicide was supported by most studies, although none were designed to separate unique contributions of personality disorders from those of other types of psychopathology. Harwood and colleagues found both personality disorders and traits being more frequent in a subsample of 54 elderly suicide cases compared to age- and sex-matched controls deceased from natural causes (45). Qin determined a respectively sixfold and ninefold higher prevalence of personality disorders in older females and males who died by suicide compared to general population controls (58). In a sample of psychiatric patients aged 60 years or older, Lawrence and colleagues found that personality disorders had the fifth highest suicide rate among all principal psychiatric diagnoses in the elderly, which was more than twofold higher than in the age-matched general population of Western Australia (risk ratio of 2.1, $n=447$ ) (44). A single longitudinal study examined the prevalence of suicide in individuals with severe personality disorders: the Lausanne Study was conducted in Switzerland from 1963 to investigate aging in all former psychiatric inpatients of the Lausanne University Psychiatric Hospital $(N=5,661)$. The investigator found that personality disorders were the third

TABLE 1 | Studies with categorical measures reporting globally on personality disorders.

\begin{tabular}{|c|c|c|c|c|c|}
\hline & Study & Sample & Age (years) & PD assessment & Summary of results \\
\hline \multirow[t]{3}{*}{ Death by suicide } & $\begin{array}{l}\text { Henriksson et al., } 1995 \text { (42) } \\
\text { Finland } \\
\text { Retrospective cohort } \\
\text { study, descriptive }\end{array}$ & $\begin{array}{l}229 \text { suicides of which } \\
43 \text { older suicides }\end{array}$ & $\geq 60$ & $\begin{array}{l}\text { Interviews with relatives } \\
\text { and doctor (DSM-III-R) }\end{array}$ & $\begin{array}{l}\text { Prevalence of PDs in elderly: } \\
\text { suicide victims: } 14 \% \text {; } \\
\text { younger suicides: } 34 \%\end{array}$ \\
\hline & $\begin{array}{l}\text { Hunt et al., } 2006 \text { (52) } \\
\text { England and Wales } \\
\text { National clinical survey, } \\
\text { descriptive }\end{array}$ & $\begin{array}{l}41,959 \text { suicides of which } \\
597 \text { older suicides }\end{array}$ & $\geq 65$ & $\begin{array}{l}\text { Retrospective } \\
\text { diagnosis } \\
\text { by consultant } \\
\text { psychiatrist } \\
\text { (ICD-10) }\end{array}$ & $\begin{array}{l}\text { Suicides with PD: } \\
\text { 19\% (<25 years) } \\
15.3 \% \text { ( } 25-34 \text { years) } \\
10.8 \% \text { (35-44 years) } \\
7.8 \% \text { (45-54 years) } \\
3.3 \% \text { (55-64 years) } \\
4.0 \% \text { (65-74 years) } \\
2.3 \% \text { ( } \geq 75 \text { years) }\end{array}$ \\
\hline & $\begin{array}{l}\text { Qin, } 2011 \text { (58) } \\
\text { Denmark } \\
\text { Population study, } \\
\text { retrospective }\end{array}$ & $\begin{array}{l}\text { 1,169 suicides (4,175 older) } \\
4,231,219 \text { population controls } \\
(193,251 \text { older })\end{array}$ & $>60$ & $\begin{array}{l}\text { Coded medical records } \\
(\text { ICD-10) }\end{array}$ & $\begin{array}{l}\text { Prevalence of PDs as principal } \\
\text { diagnoses: } \\
\text { Suicides: M: } 1.5 \% \text {, F: } 4.8 \% \\
\text { Controls: M: } 0.2 \% \text {, F: } 0.5 \%\end{array}$ \\
\hline $\begin{array}{l}\text { Suicide and } \\
\text { attempt }\end{array}$ & $\begin{array}{l}\text { Lawrence et al., } 2000 \text { (44) } \\
\text { Western Australia } \\
\text { Hospitalization-based } \\
\text { population study, } \\
\text { retrospective }\end{array}$ & $\begin{array}{l}447 \text { suicides } \\
1,596 \text { attempted suicides } \\
\text { Control values: population } \\
\text { distribution }\end{array}$ & $\geq 60$ & $\begin{array}{l}\text { Medical records } \\
\text { (ICD-9) }\end{array}$ & $\begin{array}{l}\text { PD rate ratios: } \\
\text { Suicide: M: } 2.3, \mathrm{~F}: 12.3 \\
\text { Attempt: M: } 2.4, \mathrm{~F}: 11.8 \\
\text { Risk ratio (proportional hazards } \\
\text { regression of PDs as risk factors): } \\
\text { Suicide: } 2.1 \\
\text { Attempt: } 10.2\end{array}$ \\
\hline \multirow[t]{4}{*}{ Attempted suicide } & $\begin{array}{l}\text { Nieto et al., } 1992 \text { (38) } \\
\text { Spain, Barcelona } \\
\text { Retrospective } \\
\text { comparative study }\end{array}$ & $\begin{array}{l}257 \text { suicide attempters with } \\
\text { medically serious attempts } \\
\text { of which } 38 \text { elderly }\end{array}$ & $\geq 65$ & $\begin{array}{l}\text { Medical records } \\
\text { (DSM-III-R) }\end{array}$ & $\begin{array}{l}\text { PDs with no Axis-I comorbidities } \\
\text { in attempters aged } \geq 65: 5.2 \% \\
\text { All PDs in three attempter age groups: } \\
\geq 65 \text { years }(n=38): 6(15.8 \%) \\
31-64 \text { years }(n=120): 25(21.8 \%) \\
0-30 \text { years }(n=99): 45(45.5 \%) \\
\text { Oldest group different from youngest } \\
\text { group }(p=0.003)\end{array}$ \\
\hline & $\begin{array}{l}\text { Kunik et al., } 1993 \text { (39) } \\
\text { USA (PA) } \\
\text { Case-control study, } \\
\text { cross-sectional }\end{array}$ & $\begin{array}{l}143 \text { patients with major } \\
\text { depression of which } \\
37 \text { with PD }\end{array}$ & $\geq 60$ & $\begin{array}{l}\text { Consensus conference } \\
\text { (DSM-III-R) }\end{array}$ & $\begin{array}{l}\text { History of attempts: } \\
\text { patients with PD: } 35 \% \\
\text { depressed controls: } 20 \% \\
\text { Correlation (attempts-PD): } \\
\chi^{2}(1)=3.8, p=0.06\end{array}$ \\
\hline & $\begin{array}{l}\text { Draper, } 1994 \text { (40) } \\
\text { Sydney, Australia } \\
\text { Retrospective cohort study }\end{array}$ & 69 attempted suicides & $\geq 65$ & $\begin{array}{l}\text { Medical records } \\
\text { (DSM-III/III-R, ICD-9) }\end{array}$ & $\begin{array}{l}\text { Any PD diagnosis: } 26 \% \text { as } \\
\text { secondary diagnosis }\end{array}$ \\
\hline & $\begin{array}{l}\text { Miret et al., } 2010(57) \\
\text { Madrid, Spain } \\
\text { Hospitalization-based } \\
\text { population study, } \\
\text { cross-sectional }\end{array}$ & $\begin{array}{l}\text { 1,970 attempted suicides, } \\
\text { from which } 113 \text { late-life } \\
\text { attempts }\end{array}$ & $\geq 55$ & Medical records (ICD-9) & $\begin{array}{l}\text { Prevalence of PDs as } \\
\text { principal diagnoses: } \\
\text { Older attempters: } \\
n=10(8.8 \%) \\
\text { Younger attempters: } \\
n=171(22.6 \%)\end{array}$ \\
\hline
\end{tabular}

$P D$, personality disorder, $M$, males, $F$, females. 
most common baseline psychopathology after mood disorders and alcohol dependence among the 107 suicides that were carried out by patients between 57 and 77 years of age (37). The prevalence of suicide in the subgroup of patients with personality disorders was $6.8 \%$ in males and $5.4 \%$ in females $(n=266)$, respectively, more than threefold and fivefold higher than in the age- and gender-matched general population. However, the severe pathology that triggered hospitalizations in this group of patients precludes generalization of these findings to personality disorders observed in the community.

\section{Attempted Suicide}

Examining only primary diagnoses, Miret and colleagues reported a prevalence of $8.8 \%$ for personality disorders in hospitalized patients aged 50 and older who had made a recent suicide attempt $(N=113)$ (57). Draper found a higher prevalence (26\%) considering secondary diagnoses mentioned in the hospital records of 69 attempters aged 65 or above (40). In addition, Nieto and colleagues reported that personality disorders were present without comorbid Axis-I disorders in 5.2\% of 38 older adults aged 65 or above who made a medically serious suicide attempt (38). This fraction was lower than in young attempters (30 or younger) from the same study (45.5\%, $p=0.003)$, but did not differ significantly from middle-aged attempters (31-65 years) (21.8\%). Lawrence and colleagues reported a risk ratio of 10.2 for suicide attempts given a principal diagnosis of personality disorder $(n=1,596)$, almost five times higher than the 2.1 risk ratio for death by suicide (44). Examining psychiatric patients with personality disorders $(n=37)$, Kunik and colleagues found a 35\% lifetime prevalence of attempted suicide. This prevalence, however, was not significantly different from the $20 \%$ seen in the clinical control group without personality disorders $\left[n=117 ; \chi^{2}(1)=3.76, p=0.06\right]$ (39).

\section{Suicidal Ideation}

Studies found a positive association with suicidal ideation and almost all categories of pathological personality traits in late life, with the exception of histrionic and sadistic traits $(47,59,65-67)$. None of these studies, however, excluded suicide ideators with a past history of attempt. No correlation was found between the severity of pathological personality traits and the severity of suicidal ideation (47).

\section{ICD/DSM Personality Disorders in Late-Life Suicide}

Using ICD-8 personality diagnoses the abovementioned Lausanne Study found that neurotic and psychopathic (antisocial) personality disorders were the most prevalent in former

TABLE 2 | Categorical findings on separate personality disorder diagnoses in death by suicide, and qualitative findings.

\begin{tabular}{|c|c|c|c|c|c|}
\hline & Study & Sample & Age (years) & PD assessment & Summary of results \\
\hline \multirow[t]{3}{*}{ DSM/ICD } & $\begin{array}{l}\text { Harwood et al., } 2001 \text { (45) } \\
\text { England } \\
\text { Psychological autopsy } \\
\text { study; case-control study } \\
\text { in a subsample }\end{array}$ & $\begin{array}{l}100 \text { elderly suicides } \\
54 \text { included in } \\
\text { case-control part } \\
\text { Controls: } \\
54 \text { age- and gender- } \\
\text { matched natural deaths }\end{array}$ & $\geq 60$ & Informants (ICD-10) & $\begin{array}{l}\text { Prevalence of PD: } \\
\text { Suicides: } 14.8 \% \text {, controls: } 3.7 \% \\
\text { Prevalence of PD trait accentuation: } \\
\text { Suicides: } 33.3 \% \text {, controls: } 13 \% \\
\text { PDs }(n=16) \text { : } \\
\text { Anankastic }(n=4) \text {; dissocial }(n=4) ; \\
\text { histrionic }(n=4) \text {; other }(n=3) \text {; mixed }(n=5) \\
\text { PD trait accentuation }(n=28) \text { : } \\
\text { Anankastic } n=19 \text {; anxious } n=13 ; \\
\text { dependent } n=9 \text {; histrionic } n=6 ; \\
\text { other } n=10 \\
\text { Case-control part: } \\
\text { Correlation with suicide (Fisher's exact test): } \\
\text { Anankastic traits: } p=0.012 \\
\text { Anxious traits: } p=0.015\end{array}$ \\
\hline & $\begin{array}{l}\text { Harwood et al., } 2006 \text { (50) } \\
\text { England } \\
\text { Psychological autopsy } \\
\text { study, descriptive }\end{array}$ & $\begin{array}{l}23 \text { suicides without ante- } \\
\text { mortem psychiatric diagnoses } \\
\text { No controls }\end{array}$ & $\geq 60$ & Informants (ICD-10) & $\begin{array}{l}P D(n=1) \text { : dissocial }(n=1) \\
P D \text { trait accentuation }(n=10) \text { : } \\
\text { Anankastic }(n=8) ; \text { paranoid }(n=3)\end{array}$ \\
\hline & $\begin{array}{l}\text { Ciompi, } 1976(37) \\
\text { Switzerland } \\
\text { Longitudinal study in } \\
\text { psychiatric patients }\end{array}$ & $\begin{array}{l}\text { 1,891 deaths between age } 57 \\
\text { and } 77 \text { years, of which } 266 \\
\text { patients with PD (14\%) } \\
\text { Control values: average } \\
\text { population distribution }\end{array}$ & $\geq 57$ & $\begin{array}{l}\text { Medical records } \\
\text { (psychodynamic nosology of } \\
\text { the time) }\end{array}$ & $\begin{array}{l}\text { Patients with PD who died by suicide: } \\
\text { Of all male deaths }=13(6.8 \%) \\
\text { Of all female deaths }=4(5.4 \%) \\
\text { Control values in general population: } \\
\text { Suicides out of male deaths }=1.8 \% \\
\text { Suicides out of female deaths }=0.7 \% \\
\text { Most frequent PDs in suicides: } \\
\text { Psychopathic and neurotic PDs }\end{array}$ \\
\hline Qualitative & $\begin{array}{l}\text { Kjølseth et al., } 2009 \text { (56) } \\
\text { Norway } \\
\text { Qualitative psychological } \\
\text { autopsy study }\end{array}$ & $\begin{array}{l}23 \text { older suicide victims } \\
\text { No controls }\end{array}$ & $\geq 60$ & Qualitative interviews & $\begin{array}{l}\text { Life history: hard-working achievers, } \\
\text { source of help/advice for relatives } \\
\text { Personality traits: stubborn, willing } \\
\text { to do everything by themselves } \\
\text { Relationships: introverted, distant } \\
\text { or egoistic, with strong self-control }\end{array}$ \\
\hline
\end{tabular}

$P D$, personality disorder. 
psychiatric patients who died by suicide after the age of 57 (37). In the psychodynamic nosology of the time, a "neurotic personality organization" included hysterical (i.e., histrionic), depressivemasochistic (best mapping onto self-defeating personality from DSM-III), obsessive (mapping onto obsessive-compulsive), as well as avoidant personalities (81). These findings support a role of Clusters B and C in late-life suicide, which is consistent with the more recent results detailed below. As mentioned, no study reported data on specific personality disorders and attempted suicide in the elderly.

\section{Cluster A}

Paranoid Personality Disorder. In Harwood and colleagues' secondary analysis of cases without an ante-mortem psychiatric diagnosis $(N=23)$, paranoid traits were the second most frequent (13\%) (50). However, in the absence of a control group, this finding remains difficult to interpret given the relatively high prevalence of paranoid personality in the general population $(2-5 \%)(82,83)$.

There was nevertheless a positive correlation of suicidal ideation with paranoid personality in all studies that investigated it $(47,59,65,67)$.

Schizoid Personality Disorder. There is no evidence linking schizoid personality disorder to late-life suicide, in spite of the documented worsening of schizoid personality with aging (84). To the best of our knowledge, this disorder is not associated with suicidal behavior earlier in life either.
A positive correlation was however found in all studies investigating schizoid traits in suicidal ideation $(47,59,65)$.

Schizotypal Personality Disorder. No evidence linked schizotypal personality disorder to late-life suicide.

Three studies, with possibly overlapping community samples recruited in Colorado, found a positive correlation with suicidal ideation $(59,65,67)$; however, such a relationship was not confirmed by Morse and Lynch in a depressed sample with a different recruitment source (47).

Despite the high co-occurrence of schizotypal personality disorder with BPD in the general population $(85,86)$, its role in suicidal behavior remains also unclear earlier in life.

\section{Cluster B}

Antisocial (and Dissocial) Personality Disorder. Studies in younger adults have linked antisocial personality to suicide attempts $(17,87,88)$ and death by suicide (18). Moreover, antisocial personality traits appear to persist, or only partially remit with increasing age in most individuals (89), suggesting a possible high suicide risk throughout the lifetime, yet data so far remain inconclusive. The Lausanne Study found a high prevalence of psychopathic (antisocial) personality disorder in former patients who died by suicide after the age of 57 (37). Harwood and colleagues found dissocial personality disorder to be among the three most prevalent personality disorders in their study, with $4 \%$ of suicide victims reaching full diagnostic criteria for it (45).

TABLE 3 | Categorical findings on suicidal ideation.

\begin{tabular}{|c|c|c|c|c|c|}
\hline & Study & Sample & $\begin{array}{c}\text { Age } \\
\text { (years) }\end{array}$ & Assessment & Summary of results \\
\hline \multirow[t]{5}{*}{ DSM-IV-TR } & $\begin{array}{l}\text { Segal et al., } 2012 \text { (59) } \\
\text { USA (CA) } \\
\text { Cross-sectional }\end{array}$ & $\begin{array}{l}109 \text { community- } \\
\text { dwelling older adults } \\
\text { evaluated for SI }\end{array}$ & $\geq 65$ & $\begin{array}{l}\text { SI scale: GSIS } \\
\text { PD scale: Coolidge } \\
\text { Axis-II Inventory }\end{array}$ & $\begin{array}{l}\text { Positive correlation with SI: all PDs except histrionic } \\
\text { Positive predictor of SI: borderline PD } \\
\text { Negative predictor of SI: histrionic PD }\end{array}$ \\
\hline & $\begin{array}{l}\text { Segal et al., } 2015(66) \\
\text { USA (CA) } \\
\text { Cross-sectional }\end{array}$ & & & & $\begin{array}{l}\text { Positive correlation of SI with former PDs: } \\
\text { depressive PD }\end{array}$ \\
\hline & $\begin{array}{l}\text { Jahn et al., } 2015 \text { (65) } \\
\text { USA (CA) } \\
\text { Cross-sectional }\end{array}$ & $\begin{array}{l}143 \text { community- } \\
\text { dwelling older adults } \\
\text { evaluated for SI }\end{array}$ & $\geq 65$ & $\begin{array}{l}\text { SI scale: GSIS } \\
\text { PD scale: SCID-II-PQ }\end{array}$ & $\begin{array}{l}\text { Positive correlation with SI (in decreasing order): } \\
\text { avoidant, schizotypal, depressive, borderline, schizoid, } \\
\text { dependent, passive-aggressive, and paranoid } \\
\text { personality traits } \\
\text { No significant correlation: obsessive-compulsive, } \\
\text { narcissistic, histrionic, and antisocial traits }\end{array}$ \\
\hline & $\begin{array}{l}\text { Eades et al., } 2016 \text { (67) } \\
\text { USA (CA) } \\
\text { Cross-sectional }\end{array}$ & $\begin{array}{l}102 \text { community- } \\
\text { dwelling older adults } \\
\text { evaluated for SI }\end{array}$ & $\geq 61$ & $\begin{array}{l}\text { SI scale: GSIS } \\
\text { PD scale: Coolidge } \\
\text { Axis-II inventory }\end{array}$ & $\begin{array}{l}\text { Positive correlation with SI (in decreasing order): } \\
\text { Depressive, schizoid, schizotypal, passive-aggressive, } \\
\text { avoidant, paranoid, borderline, dependent, obsessive- } \\
\text { compulsive, and self-defeating } \\
\text { No significant correlation: histrionic, antisocial, sadistic }\end{array}$ \\
\hline & $\begin{array}{l}\text { Morse and } \\
\text { Lynch, } 2004 \text { (47) } \\
\text { USA } \\
\text { Cross-sectional }\end{array}$ & $\begin{array}{l}63 \text { depressed } \\
\text { inpatients, from } \\
\text { which } 17 \text { with PD }\end{array}$ & $\geq 64$ & $\begin{array}{l}\text { SI scale: ASIQ } \\
\text { PD scale: WISPI }\end{array}$ & $\begin{array}{l}\text { SI: no significant correlation with total } \\
\text { personality disorders }\end{array}$ \\
\hline DSM-III \& -IV & $\begin{array}{l}\text { Heisel et al., } 2007 \text { (53) } \\
\text { Canada } \\
\text { Cross-sectional, } \\
\text { case-control study }\end{array}$ & $\begin{array}{l}538 \text { depressed elderly; } \\
20 \text { with narcissistic PD } \\
(n=13) / P D \text { traits }(n=7)\end{array}$ & $\geq 65$ & $\begin{array}{l}\text { SI scale: HRSD } \\
\text { suicide item } \\
\text { PD diagnosis: } \\
\text { medical records }\end{array}$ & $\begin{array}{l}\text { Narcissistic PD: positive predictor of } \mathrm{SI} \\
\text { Narcissistic PD traits: not significant predictors }\end{array}$ \\
\hline
\end{tabular}

$P D$, personality disorder; SI, suicidal ideation; GSIS, Geriatric Suicide Ideation Scale; SCID-II-PQ, Structured Clinical Interview for DSM-IV-TR Axis II-Personality Questionnaire; ASIQ, Adult Suicide Ideation Questionnaire; WISPI, Wisconsin Personality Disorders Inventory IV; HRSD, Hamilton Rating Scale for Depression. 
However, in the case-control part of their study $(n=54)$, the prevalence of antisocial personality did not differ between suicide victims and controls.

While one study (59) found an association between antisocial traits and suicidal ideation in old age, three others did not (47, $65,67)$.

Borderline (and Emotionally Labile) Personality Disorder $(B P D)$. In spite of its important role in suicides earlier in life, BPD showed no significant association with death by suicide in old age. Moreover, two studies found a significantly lower prevalence of BPD in both elderly suicides and controls than in younger age groups $(42,58)$, which is unsurprising given that most features of BPD tend to remit with age (90).

However, all studies investigating suicidal ideation found a positive correlation with borderline personality traits $(47,59$, $65,67)$. Segal and colleagues also identified borderline traits as the only positive predictor of suicidal ideation in a community sample of 109 adults aged 60 or above (59).

As mentioned earlier, BPD in old age may be subject to a survival bias. In a 27-year long longitudinal study in BPD patients $(N=165)$, Paris and Zweig-Frank reported death by suicide in as many as $10.3 \%$ of their sample with a mean age at death of 37.2 years (91). Despite persisting problems with interpersonal functioning, the surviving cohort showed significant improvement, with only five patients meeting full criteria for BPD by the end of the follow-up. Although an increase in attempts' lethality with advancing age has been reported by Soloff and colleagues (87), Pompili and colleagues' meta-analysis of suicide in BPD found a higher incidence of suicides in short-term follow-ups, suggesting lower suicidal rates during the chronic phases of BPD (92). Overall, these findings suggest that suicide risk decays, albeit incompletely, in the borderline patients who survive to old age.

Histrionic Personality Disorder. Even though histrionic personality is considered to be only mildly impairing and not linked to major emotional disability in the general population (82), Harwood and colleagues found full diagnostic criteria for histrionic personality disorder in 4 out of 100 individuals who died by suicide. Moreover, they found subthreshold histrionic traits in six others, making this personality construct the third most frequent in their sample, and the most prevalent Cluster B disorder (45). As discussed earlier, hysterical (former version of histrionic) disorder was also associated with suicides in the Lausanne Study (37).

These findings contrast with the absence of positive correlation found between suicidal ideation in old age and histrionic personality $(47,59,65,67)$. This disorder was in fact the only negative predictor of suicidal ideation in Segal and colleagues' study (59), corroborating a potential protective impact on suicide risk.

In younger adults, a protective effect of comorbid histrionic personality disorder was found in an adult sample of female attempters with BPD (93).

Narcissistic Personality Disorder. To date, no definite association has been found between narcissistic personality disorder and death by suicide in old age. However, in a qualitative psycho- logical autopsy study conducted by Kjølseth and colleagues with the informants of 23 elderly who died between 65 and 90 years of age in Norway, the majority of suicide victims were described as self-centered over-achievers, with a need to control others, sometimes despite generating conflicts due to their authoritarianism (56).

Narcissistic personality disorder was positively correlated with late-life suicidal ideation in all studies $(47,59,67)$ but one $(65)$. In addition, it was a predictor of suicidal ideation in a retrospective database analysis specifically focusing on narcissistic personality in adults aged 65 years and older $(N=538)(53)$.

Narcissistic personality disorder has been identified as a risk factor for suicide in middle-aged adults by a 10-year long longitudinal study reporting a positive correlation between narcissistic personality and number of suicide attempts in a clinical sample of 431 middle-aged adults (aged 18-45 years upon enrollment) (15). In the clinical literature, Kernberg also implicated pathological narcissism in existential crises in the second half of life (94). He discussed how suicide may appeal to narcissistic patients as a means of relieving guilt over past mistakes or missed opportunities for greatness, as "external reality gradually demonstrates [that their grandiose] fantasies are no longer viable." This risk may likely persist after age 50 . However, the low general prevalence of narcissistic personality disorder, estimated at $0.8 \%$ (83), suggests that higher-powered studies are needed to detect a potential association.

\section{Cluster C}

Avoidant (and Anxious) Personality Disorder. Despite an absence of subjects meeting full criteria for anxious personality disorder, Harwood and colleagues found a higher rate of anxious personality trait accentuation in suicide victims than in natural death controls, with $13 \%$ of suicide victims displaying anxious traits (45).

Furthermore, avoidant personality disorder was positively correlated with suicidal ideation in all studies $(47,59,65,67)$.

Age-related social isolation is possibly more pronounced in avoidant individuals, as the traits related to social ineptitude were found among the disorder's most stable diagnostic criteria (95). Avoidant personality disorder in the elderly is also highly prevalent in dysthymic disorder (73), an independent risk factor for suicide (96). Some evidence alternatively supports a lifelong risk between avoidant personality disorder and both suicide attempts (97) and death by suicide earlier in life (18).

Dependent Personality Disorder. Dependent personality disorder has a high prevalence in the general elderly population (76) and has been associated with suicides and suicide attempts earlier in life $(18,85)$. Nevertheless, this disorder showed no significant association with death by suicide in old age.

A positive correlation between dependent personality traits and suicidal ideation was found in most $(59,65,67)$, but not all studies (47).

Obsessive-Compulsive (and Anankastic) Personality Disorder $(O C P D)$. OCPD displays the strongest association with death by suicide in the existing studies, although the relationship is thin and the studies lack adequate controls. In Harwood and 
colleagues' psychological autopsy study $(N=100)$, out of the 44 suicide victims with personality pathology there were 23 cases (52.3\%) with anankastic (obsessive-compulsive) personality disorder $(n=4)$ or trait accentuation $(n=19)$. OCPD was also associated with suicide in the case-control part of the study $(n=54)$. In a secondary analysis examining subjects without a psychiatric diagnosis, anankastic personality trait accentuation was present in $8 / 23$ subjects (34.8\%) (50). Some of the personality characteristics described by Kjølseth and colleagues' qualitative findings also map onto OCPD, such as reluctance to accept help from others, self-discipline, high professional competence, hard-work, introversion, and stubbornness $(N=23)(56)$.

Evidence of the association between OCPD and suicidal ideation remains inconsistent, with two studies reporting a positive correlation $(59,67)$ and two others reporting none $(47,65)$.

OCPD is the most common personality disorder in the general population, with a prevalence of $3-8 \%$ (98). It is also the personality disorder with the highest prevalence (17.1\%) among elderly patients with dysthymic disorder (73, 99), which, as mentioned previously, is independently associated with late-life suicide (96). Along with schizoid personality disorder, OCPD is one of only two Axis-II conditions found to become accentuated in old age $(84,100)$, even in individuals who seemed unimpaired earlier in life $(101,102)$. Consistent with the qualitative findings of Kjølseth, three OCPD traits related to cognition and interpersonal functioning seem to display a stable and long-lasting pattern: preoccupation with details, rigidity and stubbornness, and reluctance to delegate $(95,103)$. These characteristics could cause a perception of loss of control in old age stemming from physical and cognitive decline, leaving suicide as a way to regain control. Supporting this hypothesis, two qualitative psychological autopsy reports examined elderly suicide victims who had, respectively, the conviction of having cancer $(n=8)$ or a chronic dyspnea diagnosis $(n=14)$, and both described a similar, rigid personality style in a majority of cases (5/8 and $12 / 14$, respectively) (104, 105). In studies of decision-making, an extreme willingness to wait for delayed rewards has been found in both OCPD patients and high-lethality older attempters, indicating their common tendency to focus on long-term rewards, without considering alternate solutions $(106,107)$. The extent to which OCPD patients premeditate attempts, however, remains subject to controversy. Whereas some case-control studies in clinical adult samples support the notion of single attempts in OCPD (108), others report a more borderline-like pattern with impulsive suicidal behavior, multiple attempts, and lower intent to die (16). In a series of case reports on high-lethality first time suicide attempters with a double-diagnosis of OCPD and mood disorders, 6/7 cases were aged 56 or above, and all of them described transient, sudden loss of control preceding their suicidal act (109). However, this behavior may be attributed as much to impulsivity as to a general lack of perspective of alternative options.

\section{Five-Factor Model}

See Table 5 for a summary of findings.

\section{Neuroticism}

Although high neuroticism has been linked to death by suicide in younger age groups (41), older psychiatric patients who died by suicide displayed lower levels of neuroticism than both their younger counterparts $(60,63)$, and those who survived their attempt (55). Interestingly, older victims were more similar to healthy controls than they were to attempters. Even though two studies found higher levels of neuroticism in older suicide victims than in healthy controls $(41,60)$, on the facet level, only trait depression (the tendency to feel sad) and trait self-consciousness (the tendency to be easily intimidated) were higher (41). Suicide victims and healthy controls did not significantly differ in the facets that capture negative emotional reactivity, namely vulnerability (the tendency to panic easily), trait anxiety (the tendency to worry), impulsiveness (the tendency to act impulsively), and anger-hostility (the tendency to get angry easily) (41). Angerhostility was also the only similar facet between suicide victims and attempters (55).

Among older suicide attempters, two studies conducted in Hong Kong, China, found increased levels of neuroticism compared to healthy controls $(49,62)$, but this finding did not survive controlling for current major depression, past suicide attempts, physical comorbidities, demographic factors, and life events in one of them (49). Other studies observed no difference from healthy controls (61), or depressed controls (48). Again, differences emerged at the facet level, with higher levels of all facets in attempters than in depressed controls, except for trait anxiety and anger-hostility (48). Lower trait anxiety was in fact found to be a predictor of the attempter status, while lower anger-hostility was associated with fewer attempts, higher lethality of method, and higher intent to die (46). Compared to healthy controls, higher levels of anger-hostility predicted attempter status in men, but not in women, while higher impulsivity was observed in elderly attempters of both sexes (62).

Higher levels of neuroticism unequivocally differentiated elderly suicide ideators from healthy controls $(59,64)$. However, in depressed samples, only one (43) out of three studies found higher levels of neuroticism in ideators than in controls, with the others reporting no difference $(48,51)$. Higher trait depression was the only facet that correlated with the severity of suicidal ideation from the neuroticism domain in a sample of depressed elderly (48), indicating that differences may be limited to only isolated facets.

\section{Extraversion}

Lower levels of extraversion were found in older adults who died by suicide compared to healthy controls in some $(49,60)$, but not all studies (41). Furthermore, in Tsoh and colleagues' study, the effect disappeared in the multivariate analysis that controlled for current major depression, past suicide attempts, physical comorbidities, demographic factors, and life events (49). Extraversion did not distinguish between older adults who died by suicide and those who only attempted it $(49,55)$.

Findings examining elderly suicide attempters and ideators were also inconclusive. Three studies using the same recruitment source found that elderly depressed inpatients who made an attempt at age 50 or older had lower levels of extraversion than depressed controls, both globally, and for the specific facets of gregariousness (seeking company of others), warmth (making friends easily), and positive emotions (tendency to be joyful) (43, $46,48)$. In addition, lower positive emotions were identified as 
an independent predictor of a greater number of attempts (46). However, older suicide attempters did not differ from general population controls on extraversion in two other studies controlling for age, sex, and major depression $(49,61)$. These inconsistent findings may be explained by sex differences, since lower levels of extraversion were present in elderly male, but not female attempters in a sex-stratified study (62). A sampling bias cannot be excluded, however. Alternatively, given the higher age cutoff in the three latter studies (65-75 years), this inconsistency might arise from a survival bias, as higher levels of extraversion have been associated with a decreased risk of death in the elderly (110).

Similarly to elderly attempters, suicide ideators aged 50 or older differed from depressed controls by reporting lower levels of both warmth and positive emotions in two studies having the same recruitment source as the three studies mentioned earlier $(48,51)$. They did not differ from healthy controls on extraversion

TABLE 4 | Characteristics of studies with dimensional findings (see Table 5 for a summary of findings).

\begin{tabular}{|c|c|c|c|c|}
\hline \multicolumn{2}{|l|}{ Study } & \multirow{4}{*}{$\begin{array}{l}\text { Sample } \\
52 \text { suicides } \\
30 \text { healthy controls }\end{array}$} & \multirow{4}{*}{$\begin{array}{l}\text { Age (years) } \\
\geq 50\end{array}$} & \multirow{4}{*}{$\begin{array}{l}\text { Assessment } \\
\text { NEO-PI }\end{array}$} \\
\hline \multirow[t]{9}{*}{ Suicide } & Duberstein et al., 1994 (41) & & & \\
\hline & USA (NY, Rochester) & & & \\
\hline & Psychological autopsy study & & & \\
\hline & De Leo et al., 2013 (60) & 261 suicides, of which 73 older & $\geq 60$ & NEO-FFI \\
\hline & Australia (QLD, NSW) & 182 sudden death controls & & \\
\hline & Case-control study & of which 79 older & & \\
\hline & Draper et al., 2014 (63) & & & \\
\hline & Australia (QLD, NSW) & & & \\
\hline & Case-control study & & & \\
\hline \multirow{6}{*}{$\begin{array}{l}\text { Suicide, attempted } \\
\text { suicide }\end{array}$} & Tsoh et al., 2005 (49) & 67 suicide victims & $\geq 65$ & NEO-FFI \\
\hline & China (Hong Kong) & 66 suicide attempters & & \\
\hline & Case-control study & 91 healthy controls & & \\
\hline & Useda et al., 2007 (55) & 60 depressed attempters & $\geq 50$ & NEO-PI-R \\
\hline & USA (NY, Rochester) & 43 suicides & & \\
\hline & Case-control study & & & \\
\hline \multirow[t]{9}{*}{ Attempted suicide } & Seidlitz et al., 2001 (46) & 45 depressed attempters & $\geq 50$ & NEO-PI-R (emotion facets) \\
\hline & USA (NY, Rochester) & 36 depressed controls & & \\
\hline & Case-control study & & & \\
\hline & Wiktorsson et al., 2013 (61) & 72 hospitalized attempters & $\geq 75$ & EPI ( $N$ and E subscales) \\
\hline & Sweden & 288 healthy controls & & \\
\hline & Case-control study & & & \\
\hline & Chan et al., 2014 (62) & 77 suicide attempters & $\geq 65$ & NEO-FFI \\
\hline & China (Hong Kong) & 99 healthy controls & & NEO-PI facets \\
\hline & Case-control study & & & \\
\hline \multirow{8}{*}{$\begin{array}{l}\text { Attempted suicide, } \\
\text { suicidal ideation }\end{array}$} & Duberstein et al., 2000 (43) & 45 depressed attempters & $\geq 50$ & SSI \\
\hline & USA (NY, Rochester) & 32 patients with recent suicidal ideation & & NEO-PI-R \\
\hline & Case-control study & (1 week) & & \\
\hline & & 61 patients without recent SI & & \\
\hline & & 36 depressed controls & & \\
\hline & Useda et al., 2004 (48) & 67 depressed attempters & $\geq 50$ & SSI \\
\hline & USA (NY, Rochester) & 43 depressed controls & & NEO-PI-R \\
\hline & Case-control study & + Assessment of severity of $\mathrm{SI}$ & & \\
\hline \multirow[t]{12}{*}{ Suicidal ideation } & Heisel et al., 2006 (51) & 32 depressed suicide ideator & $\geq 50$ & SSI \\
\hline & USA (NY, Rochester) & 101 depressed controls & & NEO-PI-R \\
\hline & Case-control study & & & \\
\hline & Hirsch et al., 2007 (54) & 462 older adults recruited from a primary & $\geq 65$ & SCID and HRSD (SI questions) \\
\hline & USA (NY, Rochester) & care setting of which 37 suicide ideators & & $\mathrm{NEO}-\mathrm{FFI}$ \\
\hline & Case-control study & & & \\
\hline & Segal et al., 2012 (59) & 109 community-dwelling elderly & $\geq 65$ & GSIS \\
\hline & USA (CO, Colorado Springs) & & & NEO-FFI \\
\hline & Cross-sectional & & & \\
\hline & Kim and Ahn, 2014 (64) & 220 community-dwelling elderly Korean & $\geq 60$ & SSI \\
\hline & USA (LA) & immigrants & & EPQR ( $N$ subscale) \\
\hline & Cross-sectional & & & \\
\hline
\end{tabular}

SI, suicidal ideation; NEO-PI, NEO Personality Inventory, NEO-FFI, NEO Five-Factor Inventory; EPI, Eysenck Personality Inventory; EPQR, Eysenck Personality Questionnaire; SSI, Scale for Suicide Ideation; SCID, Structured Clinical Interview; HRSD, Hamilton Rating Scale for Depression; NEO-PI, NEO Personality Inventory; NEO-PI-R, NEO Personality Inventory Revised; GSIS, Geriatric Suicide Ideation Scale. 
in a community-based sample aged 60 or older $(N=109)(59)$. From the three subcomponents of extraversion derived from NEO-FFI self-reports, positive affect (being joyful), but not sociability (being outgoing and sociable) or activity (tendency to be energetic and busy), was identified as a negative predictor for suicidal ideation (54).

The fact that distinctively socially oriented facets of extraversion (namely, warmth, positive emotions, and gregariousness) differentiated elderly suicide attempters from depressed controls may suggest that a tendency toward social isolation could predispose to suicidal behavior in old age. Even though younger individuals who died by suicide were also found to have lower levels of extraversion than healthy controls $(20,41)$, in their case, lower levels of activity (being frequently busy) and assertiveness (tendency to take charge) were distinguishing facets in addition to lower positive emotions (41).

TABLE 5 | Summary of dimensional findings on death by suicide, attempted suicide, and suicidal ideation.

\begin{tabular}{|c|c|c|c|}
\hline Domains; facets & Suicide victims & Suicide attempters & Suicide ideators \\
\hline Neuroticism & $\begin{array}{l}>\mathrm{HC}(41,60), \approx \mathrm{HC}(49)^{\mathrm{a}, \mathrm{b}} \\
<\mathrm{SA}(55)^{\mathrm{a}, \mathrm{b}}, \approx \mathrm{SA}(49)^{\mathrm{a}} \\
<\operatorname{ySV}(60)(63)^{\mathrm{c}}\end{array}$ & $\begin{array}{l}>\mathrm{HC}(62), \approx \mathrm{HC}(49)^{\mathrm{a}, \mathrm{b}}(61)^{\mathrm{b}} \\
\approx \mathrm{DC}(43)\end{array}$ & $\begin{array}{l}>\mathrm{HC}(59)(64)^{\mathrm{a}} \\
>\mathrm{DC}(43), \approx \mathrm{DC}(51)^{\mathrm{a}, \mathrm{b}}\end{array}$ \\
\hline Depression & $>H C(41) ;<S A(55)^{a, b}$ & $\approx D C(46,48)$ & $>D C(48)$ \\
\hline Self-consciousness & $>H C(41) ;<S A(55)^{a, b}$ & $>D C(48), \approx D C(46)$ & $\approx D C(48)$ \\
\hline Impulsiveness & $\approx H C(41) ;<S A(55)^{a, b}$ & $>H C(62) ;>D C(48)$ & $\approx D C(48)$ \\
\hline Vulnerability & $\approx H C(41) ;<S A(55)^{a, b}$ & $>D C(48)$ & $\approx D C(48)$ \\
\hline Anxiety/negative affect ${ }^{g}$ & $\approx H C(41) ;<S A(55)^{a, b}$ & $<D C(46), \approx D C(48)$ & $\approx H C(54)^{a, b, g} ; \approx D C(48)$ \\
\hline Anger-hostility & $\approx H C(41) ; \approx S A(55)^{a, b}$ & $\begin{array}{l}>H C(62)^{e}, \approx H C(62)^{f} \\
\approx D C(46,48) \\
\text { More attempts }(46) \\
\text { Lower lethality and intent }(46)\end{array}$ & $\approx D C(48)$ \\
\hline Extraversion & $\begin{array}{l}<H C(60), \approx H C(41)(49)^{a, b} \\
\approx \operatorname{SA}(49)^{a}(55)^{a, b} \\
\approx \operatorname{ySV}(60,63)\end{array}$ & $\begin{array}{l}<\mathrm{HC}(62)^{\mathrm{e}}, \\
\approx \mathrm{HC}(49)^{\mathrm{a}, \mathrm{b}}(61)^{\mathrm{b}}(62)^{\mathrm{f}} \\
<\mathrm{DC}(43) \\
\text { Fewer attempts }(43)\end{array}$ & $\begin{array}{l}\approx H C(59) \\
\approx D C(51)^{a, b}\end{array}$ \\
\hline Positive emotions/positive affect ${ }^{g}$ & No data & $\begin{array}{l}<D C(46)(48)^{a, b} \\
\text { Fewer attempts (46) (48) }\end{array}$ & $<H C(54)^{a, b, g} ;<D C(48)$ \\
\hline Warmth & No data & $\approx D C(46,48)$ & $<D C(48)^{a, b}$ \\
\hline Gregariousness/sociabilityg & No data & $\approx D C(48)$ & $\approx H C(54)^{a, b, g} ; \approx D C(48)$ \\
\hline Openness to experience & $\begin{array}{l}<\mathrm{HC}(41), \approx \mathrm{HC}(49)^{\mathrm{a}, \mathrm{b}}(60) \\
\approx \mathrm{SA}(49)^{\mathrm{a}}(55)^{\mathrm{a}, \mathrm{b}} \\
>\operatorname{ySV}(41)(60)(63)^{\mathrm{c}}\end{array}$ & $\begin{array}{l}\approx \mathrm{HC}(49)^{\mathrm{a}, \mathrm{b}}(62) \\
\approx \mathrm{DC}(48)\end{array}$ & $\begin{array}{l}\approx \mathrm{HC}(59) \\
>\mathrm{DC}(43)(51)^{\mathrm{a}, \mathrm{b}} \\
\approx \mathrm{DC}(48)\end{array}$ \\
\hline Openness to esthetics & $<H C(41)$ & $\approx D C(48)$ & No data \\
\hline Openness to action & $<H C(41) ;<y S V(41)$ & $\approx D C(48)$ & No data \\
\hline Conscientiousness & $\begin{array}{l}\approx \operatorname{HC}(41)(49)^{\mathrm{a}, \mathrm{b}}(60) \\
>\mathrm{SA}(49)^{\mathrm{a}}(55)^{\mathrm{a}, \mathrm{b}} \\
>\mathrm{ySV}(60)(63)^{\mathrm{d}}\end{array}$ & $\begin{array}{l}<H C(49)^{a}(62)^{e} \\
\approx H C(62)^{\dagger} \\
\approx D C(43)\end{array}$ & $\begin{array}{l}\approx H C(59) \\
\approx D C(48)(51)^{a, b}\end{array}$ \\
\hline Dutifulness & $>S A(55)^{a, b}$ & $\approx D C(48)$ & No data \\
\hline Achievement-striving & $>S A(55)^{a, b}$ & $\approx D C(48)$ & No data \\
\hline Self-discipline & $>S A(55)^{a, b}$ & $\approx D C(48)$ & No data \\
\hline Deliberation & $>S A(55)^{a, b}$ & $\approx D C(48)$ & No data \\
\hline Agreeableness & $\begin{array}{l}\approx \mathrm{HC}(41)(49)^{\mathrm{a}, \mathrm{b}}(60) \\
\approx \mathrm{SA}(49)^{\mathrm{a}}(55)^{\mathrm{a}, \mathrm{b}} \\
\approx \mathrm{ySV}(6063)\end{array}$ & $\begin{array}{l}\approx H C(49)^{a, b}(62) \\
\approx D C(43)\end{array}$ & $\begin{array}{l}\approx H C(59) \\
<D C(43) \\
\approx D C(48)(51)^{a, b}\end{array}$ \\
\hline Modesty & No data & $\begin{array}{l}>D C(48)^{a, b} \\
\text { More attempts }(48)^{c}\end{array}$ & $>D C(48)^{a, b}$ \\
\hline
\end{tabular}

All five domains of the Five-Factor Model and their facets with significant findings are displayed with corresponding references.

$>$, higher levels than; <, lower levels than; $\approx$, not statistically different from; HC, healthy controls; DC, depressed controls; SA, elderly suicide attempters; ySV, younger suicide victims.

${ }^{a}$ Result after adjusting for general health status (physical and/or cognitive).

${ }^{b}$ Result after adjusting for psychiatric status (any Axis-I pathology or depression).

In psychiatric subgroup.

In non-psychiatric subgroup.

eMales.

${ }^{f}$ Females.

gSubcomponents derived from the NEO-FFI. 


\section{Openness to Experience}

Findings with respect to openness to experience in late-life suicide are inconsistent across studies comparing older suicide victims either to healthy controls or to older attempters. In comparison with healthy controls, Duberstein and colleagues initially found lower levels of openness to experience in older adults who died by suicide, with significant differences in the openness to esthetics (sensitivity to any form of art), and in the openness to action facets (preference of variety to routine) (41). These findings were, however, not replicated in further studies (when considering adjusted odds ratios in Tsoh and colleagues' study) $(49,60)$. Compared to attempters, elderly victims were found to have either lower or not significantly different levels of openness to experience $(49,55)$. The effect of age was more consistent, with older suicide victims displaying lower levels of openness than their younger counterparts $(41,60,63)$. Duberstein and colleagues identified that the greatest difference between the two age groups was in openness to action, indicating a higher preference for routine in older versus younger suicide victims (41).

Elderly suicide attempters showed no difference in openness to experience compared to healthy as well as depressed controls $(46,48,49,62)$.

In older suicide ideators, some $(43,51)$ but not all studies (48) found higher openness to experience when compared to depressed controls. No difference was found between ideators and healthy controls (59).

Thus, the role of openness to experience in late-life suicide remains unclear. According to Duberstein, lower levels of openness to experience in older suicide victims (compared to younger victims and healthy controls) may arise from a reduced capability to cope with age-related changes or losses due to excessive, short-sighted, concrete thinking and a rigidly defined self-image (111). Consistent with this theory, higher levels of openness to experience have been positively associated with volunteer work and better cognition in old age (10). It is, however, also possible that the lower levels of openness to action found in older versus younger adults who died by suicide may arise from a maturational effect, since a decrease in this facet has been associated with normal aging (112).

\section{Conscientiousness}

Higher levels of conscientiousness distinguished older suicide victims from younger victims $(60,63)$, as well as from older attempters in clinical samples $(49,55)$. The difference with attempters was also apparent at the facet level, where suicide victims displayed higher dutifulness (proneness to follow the rules), achievement-striving (tendency to work-hard/overachieve), and self-discipline (capability to get things done when needed) (55). Of three studies $(41,49,60)$, only Tsoh and colleagues found lower levels conscientiousness in elderly suicide victims compared to general population controls in a univariate analysis, but the finding did not survive controlling for current major depression, past suicide attempts, physical comorbidities, sociodemographic factors and life events (49).

Studies comparing elderly suicide attempters versus general population controls found either lower conscientiousness in attempters (49) or similar levels in the two groups (61). No differences were found between older suicide attempters and depressed controls $(43,48)$. In a sex-stratified study, lower levels of conscientiousness were present in elderly male attempters compared to healthy controls, although no such difference was found in females (62).

Elderly suicide ideators showed no difference in their levels of conscientiousness compared to healthy or depressed controls $(48,51,59)$.

Overall, higher levels of conscientiousness seem to discriminate suicides from unsuccessful attempts in depressed older adults, as well as late-onset suicides from early-onset ones. These relatively higher levels of conscientiousness in older suicides appear to be consistent with ICD/DSM-findings reporting an association with OCPD (see in the corresponding subsection). In a meta-analysis, OCPD was the only Axis-II diagnosis positively correlated with conscientiousness (113). Although higher levels of conscientiousness have been linked to several facets of successful aging $(10,114)$, the above findings suggest that this trait could also contribute to negative outcomes in late life, especially when co-occurring with depression.

\section{Agreeableness}

Studies have found no difference in agreeableness in older suicide victims compared to younger victims, healthy controls, and elderly attempters $(41,49,55,60,63)$. Although Tsoh and colleagues found that elderly who died by suicide had higher levels of agreeableness than elderly attempters, this effect did not hold in the multivariate model controlling for current depressive disorder, history of suicide attempt, physical comorbidities, demographic factors, and life events (49).

No study found overall differences in agreeableness between elderly suicide attempters and healthy or depressed controls, with the exception of the unadjusted effect reported by Tsoh and colleagues that indicated lower levels of agreeableness in attempters $(43,49,61,62)$.

With respect to elderly suicide ideators, most studies found no difference in agreeableness compared to both healthy and depressed controls $(48,51,59)$.

Thus, agreeableness does not seem to distinguish older adults who attempt or die by suicide from the general elderly population.

\section{DISCUSSION}

\section{Main Findings}

Maladaptive personality seems to play a role in suicidal behavior in old age, although it is most often present in milder, subthreshold forms. The existing literature points toward heterogeneity in personality profiles of older adults with suicidal ideation or behavior. Suicidal ideation was predicted by narcissistic and borderline personality and was positively associated with all other personality disorders as indicated by at least one study, with the exception of histrionic personality. By contrast, only obsessivecompulsive and avoidant personality disorders were implicated in death by suicide, although this association may be confounded by depression. 
Studies using the Big Five further characterized older adults who died by suicide as being more neurotic than healthy individuals, but less neurotic and more conscientious than older adults who only carried out non-fatal attempts. The limited evidence that we have links maladaptive personality with recurrent suicide attempts of largely lower severity. For example, lower anger-hostility was associated with a smaller number of attempts, higher lethality of method and higher intent to die, while lower positive emotions were identified as an independent predictor of a greater number of attempts (46).

We take these findings as evidence that a subset of aging individuals with personality disorders, BPD being the prototype, continue to display chronic suicidal ideation and repeated suicide attempts. On the other hand, the emergence of serious suicidal behavior in late life is associated with more intact personality in a majority of individuals and, possibly, obsessive-compulsive traits in a significant minority.

An important alternative hypothesis is that dysfunctional personality traits involved in late-life suicide are not well captured by existing criteria and measures, possibly reflecting effects of neurodegeneration and other aspects of brain aging. Cognitive rigidity, for instance, often appears in qualitative case descriptions and may sensitize older adults to acute stressors $(56,104,105)$. It is, however, only partially captured by categorical OCPD criteria, higher conscientiousness, and lower openness to action (a facet of openness to experience), which may be overrepresented among late-life vs. early-life suicides.

\section{Limitations}

The assessment of DSM/ICD personality disorder criteria may not be best suited for the characterization of personality in the elderly. DSM personality disorders map better onto younger than older adults in whom many of the criteria become difficult to evaluate $(115,116)$. In addition, personality assessment in psychological autopsy studies likely under-detects internalizing traits over the life course, reflected in only moderate consistency with ante-mortem Axis-II diagnoses found in adults (kappa $=0.65)(117)$. Therefore, older suicide attempters with highly medically lethal attempts probably provide the best in vivo window into death by suicide. Unfortunately, categorical data focusing on separate personality disorders in the elderly were absent in attempters, scarce in older suicide victims, and lacking comparisons with depressed non-suicidal control groups. These limitations make it impossible to draw strong conclusions about late-life suicidal behavior in patients with specific personality disorders.

Moreover, suicidal behavior is heterogeneous in its life course, planning, method selection, and medical consequences $(106,118)$. The studies reviewed here did not generally consider this heterogeneity in their design and analytic approach, and the relationship between the older individual's personality profile and the life course and characteristics of his/her suicidal behavior remains largely unexplored. More work is needed, both to identify reliable predictors of any suicidal behavior in old age and, more importantly, parse the behavior's heterogeneity.

\section{Clinical Implications}

From a clinical perspective, these results suggest that older adults who are evaluated for suicidal ideation are not necessarily representative of those who die by suicide. Among the latter individuals, only a subgroup seems to display dysfunctional personality features, with a rigid vulnerability being possibly as common as an emotionally labile one. This heterogeneity highlights the challenges in assessing suicidal risk in the elderly. One needs to be cautious in drawing conclusions from the patient's personality profile, and other risk factors such as access to firearms, depression, addiction, psychosis, and pain should be given greater weight at the current state of knowledge.

\section{Future Directions}

Disorders of aging can also alter personality. Dementia brings about a progressive personality change (119), exaggeration of existing personality traits and mood disturbances being the most frequent manifestations. A longitudinal study found that, in prodromal Alzheimer's disease, increased rigidity was the most frequent alteration, occurring in $25 \%$ of the individuals subsequently converting to dementia, closely followed by apathy (24\%), egocentricity (21\%), and impaired emotional control (18\%) (120). Other investigators reported higher levels of neuroticism, as well as lower levels of both extraversion and conscientiousness in patients with Alzheimer type dementia $(121,122)$. Similarly, higher levels of neuroticism, as well as lower levels of extraversion and goal orientation have been reported in either premorbid or beginning stages of Parkinson's disease (123-125). Such personality characteristics may be associated with alterations in the dopaminergic system and therefore predate motor symptoms of parkinsonism (126). Thus, the behavioral effects of neurodegeneration may in part explain the divergence in personality profiles between younger and older suicides. For example, it is possible that the accentuation of rigid personality traits contributes to suicide risk by impairing individuals' ability to cope with their progressive loss of cognitive abilities. Moreover, organic mental disorder may similarly contribute to the heterogeneity of personality profiles found in older adults at risk of suicide and has been linked to an overall under-detection of personality disorders in the elderly (77). Interestingly, new forms of impulsivity may also emerge in neurocognitive disorders, as in the case of the disruption of the indirect (no-go) and hyper-direct ("cortical brake") pathways by dopamine agonists and subthalamic nucleus stimulation in Parkinson's disease, where some studies point to treatment-emergent suicidal behavior $(127,128)$.

Another neurocognitive mechanism worth investigating further is executive dysfunction. This construct has already been linked to late-onset, treatment-resistant depression $(129,130)$ as well as to suicidal behavior (131). Moreover, there appears to be a correlation between deficits in executive functioning and certain personality disorders, such as antisocial, borderline and obsessive-compulsive (132-134).

The question of the best approach to characterize personality in older adults at increased risk of suicide remains open. Research is increasingly shifting toward dimensional measures, which have the advantages of being assessable through self-report and 
increasing statistical power by virtue of being parametric. Clinical constructs underlying categorical personality disorders, however, appear to possess unique explanatory and heuristic value above and beyond the Big Five in the study of suicidal behavior (135). In addition to traditional personality measures, complementary neuropsychological tools may be needed, including experimental paradigms assessing decision-making and social interactions, similarly to the way other trait-level constructs, such as impulsivity, are investigated (136).

\section{Conclusion}

Despite the scarcity of published studies, this review highlights (1) the smaller role that Cluster B personality disorders and their defining constructs play in late-life suicide compared to suicide in younger adults and (2) a possible role for Cluster $\mathrm{C}$ disorders, such as OCPD, in late-life suicide. Almost nothing is known about the contribution of personality change due to neurodegenerative and vascular diseases. The reasons for the generally lower prevalence of diagnosable personality disorders in older vs. younger adults who engage in suicidal behavior are likely to include actual change in the behavioral expression of personality across the lifespan, poorer fit of diagnostic instruments, and the contributions of neurodegenerative and vascular brain changes.

\section{REFERENCES}

1. National Institute of Mental Health (NIMH). Suicide [Internet]. (2017) [cited 2018 Feb 27]. Available from: https:/www.nimh.nih.gov/health/statistics/ suicide.shtml\#part_154969

2. American Association of Suicidology. Elderly Suicide Fact Sheet Based on 2012 Data [Internet]. (2014) [cited 2016 Dec 19]. Available from: http://www. suicidology.org/Portals/14/docs/Resources/FactSheets/Elderly2012.pdf

3. Waern M, Rubenowitz E, Runeson B, Skoog I, Wilhelmson K, Allebeck P. Burden of illness and suicide in elderly people: case-control study. $B M J$ (2002) 324(7350):1355. doi:10.1136/bmj.324.7350.1355

4. Waern M, Rubenowitz E, Wilhelmson K. Predictors of suicide in the old elderly. Gerontology (2003) 49(5):328-34. doi:10.1159/000071715

5. Juurlink DN, Herrmann N, Szalai JP, Kopp A, Redelmeier DA. Medical illness and the risk of suicide in the elderly. Arch Intern Med (2004) 164(11):1179-84. doi:10.1001/archinte.164.11.1179

6. Fässberg MM, Cheung G, Canetto SS, Erlangsen A, Lapierre S, Lindner R, et al. A systematic review of physical illness, functional disability, and suicidal behaviour among older adults. Aging Ment Health (2016) 20(2):166-94. doi:10.1080/13607863.2015.1083945

7. Mann JJ, Waternaux C, Haas GL, Malone KM. Toward a clinical model of suicidal behavior in psychiatric patients. Am J Psychiatry (1999) 156(2):181-9.

8. Heikkinen ME, Henriksson MM, Isometsä ET, Marttunen MJ, Na HM, LöNnqvist JK. Recent life events and suicide in personality disorders. J Nerv Amp Ment Dis (1997) 185(6):373-81. doi:10.1097/00005053199706000-00003

9. Devanand D. Comorbid psychiatric disorders in late life depression. Biol Psychiatry (2002) 52(3):236-42. doi:10.1016/S0006-3223(02)01336-7

10. Baek Y, Martin P, Siegler IC, Davey A, Poon LW. Personality traits and successful aging: findings from the Georgia centenarian study. Int J Aging Hum $\operatorname{Dev}$ (2016) 83(3):207-27. doi:10.1177/0091415016652404

11. Medawar PB. Uniqueness of the Individual. London: Methuen (1957).

12. Williams GC, Williams DC. Natural selection of individually harmful social adaptations among sibs with special reference to social insects. Evolution (1957) 11(1):32-9. doi:10.2307/2405809

13. Giner L, Blasco-Fontecilla H, Mercedes Perez-Rodriguez M, Garcia-Nieto R, Giner J, Guija JA, et al. Personality disorders and health problems distinguish suicide attempters from completers in a direct comparison. J Affect Disord (2013) 151(2):474-83. doi:10.1016/j.jad.2013.06.029
We would be remiss not to mention the possibility, often rejected by psychiatrists, that some proportion of late-life suicidal behavior may be rational in that it is not explained by psychopathology. Future research will reveal to what extent this may be true, and to what extent suicide in characterologically unaffected older adults is motivated by concerns such as depression, psychosis, addiction, or impaired cognition and decision-making.

\section{AUTHOR CONTRIBUTIONS}

$\mathrm{AD}$ and $\mathrm{KS}$ conceived and directed the project; AS collected data, structured and drafted the article. All authors contributed to the theoretical framework, data interpretation as well as the development of the manuscript.

\section{ACKNOWLEDGMENTS}

We thank Maria Alessi, Laura Kenneally, Ariel Eytan, and George Tsimploulis for editorial and conceptual input. This work was supported by the University of Geneva (Boninchi Foundation Fellowship and Open-Access Funds to AS; Department of Psychiatry to JA), as well as the National Institute of Medical Health (NIMH R01MH048463, R01MH100095 to AD; R01MH085651 to KS).

14. May AM, Klonsky ED, Klein DN. Predicting future suicide attempts among depressed suicide ideators: a 10-year longitudinal study. J Psychiatr Res (2012) 46(7):946-52. doi:10.1016/j.jpsychires.2012.04.009

15. Ansell EB, Wright AGC, Markowitz JC, Sanislow CA, Hopwood CJ, Zanarini $\mathrm{MC}$, et al. Personality disorder risk factors for suicide attempts over 10 years of follow-up. Personal Disord (2015) 6(2):161-7. doi:10.1037/ per0000089

16. Diaconu G, Turecki G. Obsessive-compulsive personality disorder and suicidal behavior: evidence for a positive association in a sample of depressed patients. J Clin Psychiatry (2009) 70(11):1551-6. doi:10.4088/JCP.08m04636

17. Verona E, Sachs-Ericsson N, Joiner TE. Suicide attempts associated with externalizing psychopathology in an epidemiological sample. Am J Psychiatry (2004) 161(3):444-51. doi:10.1176/appi.ajp.161.3.444

18. Foster T, Gillespie K, McClelland R, Patterson C. Risk factors for suicide independent of DSM-III-R axis I disorder. Case-control psychological autopsy study in northern Ireland. Br J Psychiatry (1999) 175(2):175-9. doi:10.1192/ bjp.175.2.175

19. Brezo J, Paris J, Turecki G. Personality traits as correlates of suicidal ideation, suicide attempts, and suicide completions: a systematic review. Acta Psychiatr Scand (2006) 113(3):180-206. doi:10.1111/j.1600-0447. 2005.00702.x

20. Fang L, Heisel MJ, Duberstein PR, Zhang J. Combined effects of neuroticism and extraversion: findings from a matched case control study of suicide in rural China. J Nerv Ment Dis (2012) 200(7):598-602. doi:10.1097/NMD. 0b013e31825bfb53

21. Pallis DJ, Jenkins JS. Extraversion, neuroticism, and intent in attempted suicides. Psychol Rep (1977) 41(1):19-22. doi:10.2466/pr0.1977.41.1.19

22. Stanković Z, Saula-Marojević B, Potrebić A. Personality profile of depressive patients with a history of suicide attempts. Psychiatr Danub (2006) 18(3-4):159-68.

23. Yen S, Siegler IC. Self-blame, social introversion, and male suicides: prospective data from a longitudinal study. Arch Suicide Res (2003) 7(1):17-27. doi:10.1080/13811110301569

24. Brodsky BS, Groves SA, Oquendo MA, Mann JJ, Stanley B. Interpersonal precipitants and suicide attempts in borderline personality disorder. Suicide Life Threat Behav (2006) 36(3):313-22. doi:10.1521/suli.2006.36.3.313

25. Rihmer Z, Benazzi F. Impact on suicidality of the borderline personality traits impulsivity and affective instability. Ann Clin Psychiatry (2010) 22(2):121-8. 
26. Stone MH, Hurt SW, Stone DK. The PI 500: long-term follow-up of borderline inpatients meeting DSM-III criteria I. Global outcome. J Personal Disord (1987) 1(4):291-8. doi:10.1521/pedi.1987.1.4.291

27. Zanarini MC, Frankenburg FR, Reich DB, Fitzmaurice G. Time to attainment of recovery from borderline personality disorder and stability of recovery: a 10-year prospective follow-up study. Am J Psychiatry (2010) 167(6):663-7. doi:10.1176/appi.ajp.2009.09081130

28. Frierson RL. Suicide attempts by the old and the very old. Arch Intern Med (1991) 151(1):141. doi:10.1001/archinte.151.1.141

29. Conwell Y, Duberstein PR, Cox C, Herrmann J, Forbes N, Caine ED. Age differences in behaviors leading to completed suicide. Am J Geriatr Psychiatry (1998) 6(2):122-6. doi:10.1097/00019442-199805000-00005

30. American Psychological Association (APA). Personality [Internet]. (2018) [cited 2018 Feb 6]. Available from: http://www.apa.org/topics/personality/ index.aspx

31. O'Carroll PW, Berman AL, Maris RW, Moscicki EK, Tanney BL, Silverman MM. Beyond the tower of Babel: a nomenclature for suicidology. Suicide Life Threat Behav (1996) 26(3):237-52.

32. Chan LF, Shamsul AS, Maniam T. Are predictors of future suicide attempts and the transition from suicidal ideation to suicide attempts shared or distinct: a 12-month prospective study among patients with depressive disorders. Psychiatry Res (2014) 220(3):867-73. doi:10.1016/j.psychres.2014.08.055

33. Suominen K, Isometsä E, Suokas J, Haukka J, Achte K, Lönnqvist J. Completed suicide after a suicide attempt: a 37-year follow-up study. Am J Psychiatry (2004) 161(3):562-3. doi:10.1176/appi.ajp.161.3.562

34. Rudd MD, Joiner T, Rajab MH. Relationships among suicide ideators, attempters, and multiple attempters in a young-adult sample. JAbnorm Psychol (1996) 105(4):541-50. doi:10.1037/0021-843X.105.4.541

35. Gil S. Suicide attempters vs. ideators: are there differences in personality profiles? Arch Suicide Res (2005) 9(2):153-61. doi:10.1080/13811110590904007

36. Brezo J, Paris J, Tremblay R, Vitaro F, HéBert M, Turecki G. Identifying correlates of suicide attempts in suicidal ideators: a population-based study. Psychol Med (2007) 37(11):1551-62. doi:10.1017/S0033291707000803

37. Ciompi L. Late suicide in former mental patients. Psychopathology (1976) 9(1):59-63. doi:10.1159/000283665

38. Nieto E, Vieta E, Lazaro L, Gasto C, Cirera E. Serious suicide attempts in the elderly. Psychopathology (1992) 25(4):183-8. doi:10.1159/000284770

39. Kunik ME, Mulsant BH, Rifai AH, Sweet R, Pasternak R, Rosen J, et al. Personality disorders in elderly inpatients with major depression. Am J Geriatr Psychiatry (1993) 1(1):38-45. doi:10.1097/00019442-19930011000006

40. Draper B. Suicidal behaviour in the elderly. Int J Geriatr Psychiatry (1994) 9(8):655-61. doi:10.1002/gps.930090810

41. Duberstein PR, Conwell Y, Caine ED. Age differences in the personality characteristics of suicide completers: preliminary findings from a psychological autopsy study. Psychiatry (1994) 57(3):213-24. doi:10.1080/00332747. 1994.11024686

42. Henriksson MM, Marttunen MJ, Isometsä ET, Heikkinen ME, Aro HM, Kuoppasalmi KI, et al. Mental disorders in elderly suicide. Int Psychogeriatr (1995) 7(2):275-86. doi:10.1017/S1041610295002031

43. Duberstein PR, Conwell Y, Seidlitz L, Denning DG, Cox C, Caine ED. Personality traits and suicidal behavior and ideation in depressed inpatients 50 years of age and older. J Gerontol B Psychol Sci Soc Sci (2000) 55(1): 18-26. doi:10.1093/geronb/55.1.P18

44. Lawrence D, Almeida OP, Hulse GK, Jablensky AV, Holman CD. Suicide and attempted suicide among older adults in Western Australia. Psychol Med (2000) 30(4):813-21. doi:10.1017/S0033291799002391

45. Harwood D, Hawton K, Hope T, Jacoby R. Psychiatric disorder and personality factors associated with suicide in older people: a descriptive and case-control study. Int J Geriatr Psychiatry (2001) 16(2):155-65. doi:10.1002/ 1099-1166(200102)16:2<155::AID-GPS289>3.0.CO;2-0

46. Seidlitz L, Conwell Y, Duberstein P, Cox C, Denning D. Emotion traits in older suicide attempters and non-attempters. JAffect Disord (2001) 66(2-3):123-31. doi:10.1016/S0165-0327(00)00300-1

47. Morse JQ, Lynch TR. A preliminary investigation of self-reported personality disorders in late life: prevalence, predictors of depressive severity, and clinical correlates. Aging Ment Health (2004) 8(4):307-15. doi:10.1080/ 13607860410001709674
48. Useda JD, Duberstein PR, Conner KR, Conwell Y. Personality and attempted suicide in depressed adults 50 years of age and older: a facet level analysis. Compr Psychiatry (2004) 45(5):353-61. doi:10.1016/j.comppsych. 2004.06.002

49. Tsoh J, Chiu HFK, Duberstein PR, Chan SSM, Chi I, Yip PSF, et al. Attempted suicide in elderly Chinese persons: a multi-group, controlled study. Am J Geriatr Psychiatry (2005) 13(7):562-71. doi:10.1097/00019442200507000-00004

50. Harwood D, Hawton K, Hope T, Jacoby R. Suicide in older people without psychiatric disorder. Int J Geriatr Psychiatry (2006) 21(4):363-7. doi:10.1002/ gps. 1473

51. Heisel MJ, Duberstein PR, Conner KR, Franus N, Beckman A, Conwell Y. Personality and reports of suicide ideation among depressed adults 50 years of age or older. J Affect Disord (2006) 90(2-3):175-80. doi:10.1016/j. jad.2005.11.005

52. Hunt IM, Kapur N, Robinson J, Shaw J, Flynn S, Bailey H, et al. Suicide within 12 months of mental health service contact in different age and diagnostic groups: national clinical survey. Br J Psychiatry (2006) 188(2):135-42. doi:10.1192/bjp.188.2.135

53. Heisel MJ, Links PS, Conn D, van Reekum R, Flett GL. Narcissistic personality and vulnerability to late-life suicidality. Am J Geriatr Psychiatry (2007) 15(9):734-41. doi:10.1097/01.JGP.0000260853.63533.7d

54. Hirsch JK, Duberstein PR, Chapman B, Lyness JM. Positive affect and suicide ideation in older adult primary care patients. Psychol Aging (2007) 22(2):380-5. doi:10.1037/0882-7974.22.2.380

55. Useda JD, Duberstein PR, Conner KR, Beckman A, Franus N, Tu X, et al. Personality differences in attempted suicide versus suicide in adults 50 years of age or older. JConsult Clin Psychol (2007) 75(1):126-33. doi:10.1037/0022-006X.75.1.126

56. Kjølseth I, Ekeberg O, Steihaug S. "Why do they become vulnerable when faced with the challenges of old age?" Elderly people who committed suicide, described by those who knew them. Int Psychogeriatr (2009) 21(5):903-12. doi:10.1017/S1041610209990342

57. Miret M, Nuevo R, Morant C, Sainz-Cortón E, Jiménez-Arriero MA, López-Ibor JJ, et al. Differences between younger and older adults in the structure of suicidal intent and its correlates. Am J Geriatr Psychiatry (2010) 18(9):839-47. doi:10.1097/JGP.0b013e3181d145b0

58. Qin P. The impact of psychiatric illness on suicide: differences by diagnosis of disorders and by sex and age of subjects. J Psychiatr Res (2011) 45(11): 1445-52. doi:10.1016/j.jpsychires.2011.06.002

59. Segal DL, Marty MA, Meyer WJ, Coolidge FL. Personality, suicidal ideation, and reasons for living among older adults. J Gerontol B Psychol Sci Soc Sci (2012) 67(2):159-66. doi:10.1093/geronb/gbr080

60. De Leo D, Draper BM, Snowdon J, Kõlves K. Suicides in older adults: a case-control psychological autopsy study in Australia. J Psychiatr Res (2013) 47(7):980-8. doi:10.1016/j.jpsychires.2013.02.009

61. Wiktorsson S, Berg AI, Billstedt E, Duberstein PR, Marlow T, Skoog I, et al. Neuroticism and extroversion in suicide attempters aged 75 and above and a general population comparison group. Aging Ment Health (2013) 17(4):479-88. doi:10.1080/13607863.2012.749835

62. Chan SMS, Chiu FKH, Lam CWL, Wong SMC, Conwell Y. A multidimensional risk factor model for suicide attempts in later life. Neuropsychiatr Dis Treat (2014) 10:1807-17. doi:10.2147/NDT.S70011

63. Draper B, Kôlves K, De Leo D, Snowdon J. A controlled study of suicide in middle-aged and older people: personality traits, age, and psychiatric disorders. Suicide Life Threat Behav (2014) 44(2):130-8. doi:10.1111/sltb. 12053

64. Kim BJ, Ahn J. Factors that influence suicidal ideation among elderly Korean immigrants: focus on diatheses and stressors. Aging Ment Health (2014) 18(5):619-27. doi:10.1080/13607863.2013.866631

65. Jahn DR, Poindexter EK, Cukrowicz KC. Personality disorder traits, risk factors, and suicide ideation among older adults. Int Psychogeriatr (2015) 27(11):1785-94. doi:10.1017/S1041610215000174

66. Segal DL, Gottschling J, Marty M, Meyer WJ, Coolidge FL. Relationships among depressive, passive-aggressive, sadistic and self-defeating personality disorder features with suicidal ideation and reasons for living among older adults. Aging Ment Health (2015) 19(12):1071-7. doi:10.1080/13607863. 2014.1003280 
67. Eades A, Segal DL, Coolidge F, Feliciano L. Suicide Among Older Adults: An Exploration of the Effects of Personality and Self-Esteem on Thwarted Belongingness, Perceived Burdensomeness, and suicidal ideation [MA Thesis]. Colorado Springs: University of Colorado, Department of Psychology (2016).

68. Costa PT, McCrae RR. Primary traits of Eysenck's P-E-N system: three- and five-factor solutions. J Pers Soc Psychol (1995) 69(2):308-17. doi:10.1037/ 0022-3514.69.2.308

69. Saucier G. Replicable item-cluster subcomponents in the NEO five-factor inventory.J Pers Assess (1998) 70(2):263-76.doi:10.1207/s15327752jpa7002_6

70. Multisite Intervention Study on Suicidal Behaviours-SUPRE-MISS: Protocol of SUPRE-MISS. World Health Organization - Multisite Intervention Study on Suicidal Behaviours 2002.

71. Mościcki EK. Gender differences in completed and attempted suicides. Ann Epidemiol (1994) 4(2):152-8. doi:10.1016/1047-2797(94)90062-0

72. Waern M, Runeson BS, Allebeck P, Beskow J, Rubenowitz E, Skoog I, et al. Mental disorder in elderly suicides: a case-control study. Am J Psychiatry (2002) 159(3):450-5. doi:10.1176/appi.ajp.159.3.450

73. Devanand DP, Turret N, Moody BJ, Fitzsimons L, Peyser S, Mickle K, et al. Personality disorders in elderly patients with dysthymic disorder. AmJ Geriatr Psychiatry (2000) 8(3):188-95. doi:10.1097/00019442-200008000-00002

74. Harrison KE, Dombrovski AY, Morse JQ, Houck P, Schlernitzauer M, Reynolds CF, et al. Alone? Perceived social support and chronic interpersonal difficulties in suicidal elders. Int Psychogeriatr (2010) 22(03):445. doi:10.1017/S1041610209991463

75. Waern M, Beskow J, Runeson B, Skoog I. Suicidal feelings in the last year of life in elderly people who commit suicide. The Lancet (1999) 354 (9182):917-8. doi:10.1016/S0140-6736(99)93099-4

76. Abrams RC, Horowitz SV. Personality disorders after age 50: a meta-analysis. J Personal Disord (1996) 10(3):271-81. doi:10.1521/pedi.1996.10.3.271

77. Kunik ME, Mulsant BH, Rifai AH, Sweet R, Pasternak R, Zubenko GS. Diagnostic rate of comorbid personality disorder in elderly psychiatric inpatients. Am J Psychiatry (1994) 151(4):603-5. doi:10.1176/ajp.151.4.603

78. Koenig HG, Meador KG, Cohen HJ, Blazer DG. Detection and treatment of major depression in older medically ill hospitalized patients. Int J Psychiatry Med (1989) 18(1):17-31. doi:10.2190/QUP8-XL19-TKXK-CRE5

79. German PS, Shapiro S, Skinner EA, Von Korff M, Klein LE, Turner RW, et al. Detection and management of mental health problems of older patients by primary care providers. JAMA (1987) 257(4):489. doi:10.1001/jama.257.4.489

80. Uncapher H, Areán PA. Physicians are less willing to treat suicidal ideation in older patients. J Am Geriatr Soc (2000) 48(2):188-92. doi:10.1111/j.15325415.2000.tb03910.x

81. Magnavita JJ. Handbook of Personality Disorders - Theory and Practice [Internet]. New Jersey, United States: John Wiley \& Sons, Inc (2004).

82. Grant BF, Hasin DS, Stinson FS, Dawson DA, Chou SP, Ruan WJ, et al. Prevalence, correlates, and disability of personality disorders in the United States: results from the national epidemiologic survey on alcohol and related conditions. JClin Psychiatry (2004) 65(7):948-58. doi:10.4088/JCP. v65n0711

83. Torgersen S, Kringlen E, Cramer V. The prevalence of personality disorders in a community sample. Arch Gen Psychiatry (2001) 58(6):590-6. doi:10.1001/ archpsyc.58.6.590

84. Engels GI, Duijsens IJ, Haringsma R, van Putten CM. Personality disorders in the elderly compared to four younger age groups: a cross-sectional study of community residents and mental health patients. JPers Disord (2003) 17(5):447-59. doi:10.1521/pedi.17.5.447.22971

85. Zimmerman M, Coryell W. DSM-III personality disorder diagnoses in a nonpatient sample: demographic correlates and comorbidity. Arch Gen Psychiatry (1989) 46(8):682. doi:10.1001/archpsyc.1989.01810080012002

86. Lentz V, Robinson J, Bolton JM. Childhood adversity, mental disorder comorbidity, and suicidal behavior in schizotypal personality disorder. J Nerv Ment Dis (2010) 198(11):795-801. doi:10.1097/NMD. 0b013e3181f9804c

87. Soloff PH, Lis JA, Kelly T, Cornelius J, Ulrich R. Risk factors for suicidal behavior in borderline personality disorder. Am JPsychiatry (1994) 151(9):1316-23. doi:10.1176/ajp.151.9.1316

88. Roth KB, Borges G, Medina-Mora M-E, Orozco R, Ouéda C, Wilcox HC. Depressed mood and antisocial behavior problems as correlates for suicide-related behaviors in Mexico. J Psychiatr Res (2011) 45(5):596-602. doi:10.1016/j.jpsychires.2010.10.009

89. Black DW, Baumgard CH, Bell SE. A 16- to 45-year follow-up of 71 men with antisocial personality disorder. Compr Psychiatry (1995) 36(2):130-40. doi:10.1016/S0010-440X(95)90108-6

90. Zanarini MC, Frankenburg FR, Reich DB, Fitzmaurice GM. Fluidity of the subsyndromal phenomenology of borderline personality disorder over 16 years of prospective follow-up. Am J Psychiatry (2016) 173(7):688-94. doi:10.1176/appi.ajp.2015.15081045

91. Paris J, Zweig-Frank H. A 27-year follow-up of patients with borderline personality disorder. Compr Psychiatry (2001) 42(6):482-7. doi:10.1053/comp. 2001.26271

92. Pompili M, Girardi P, Ruberto A, Tatarelli R. Suicide in borderline personality disorder: a meta-analysis. Nord J Psychiatry (2005) 59(5):319-24. doi:10.1080/08039480500320025

93. Shearer SL, Peters CP, Quaytman MS, Wadman BE. Intent and lethality of suicide attempts among female borderline inpatients. Am J Psychiatry (1988) 145(11):1424-7. doi:10.1176/ajp.145.11.1424

94. Kernberg OF. Internal World and External Reality. New York, United States: Jason Aronson, Inc (1980).

95. McGlashan TH, Grilo CM, Sanislow CA, Ralevski E, Morey LC, Gunderson JG, et al. Two-year prevalence and stability of individual DSM-IV criteria for schizotypal, borderline, avoidant, and obsessive-compulsive personality disorders: toward a hybrid model of axis II disorders. Am J Psychiatry (2005) 162(5):883-9. doi:10.1176/appi.ajp.162.5.883

96. Alexopoulos GS. Depression in the elderly. The Lancet (2005) 365(9475): 1961-70. doi:10.1016/S0140-6736(05)66665-2

97. Yen S, Pagano ME, Shea MT, Grilo CM, Gunderson JG, Skodol AE, et al. Recent life events preceding suicide attempts in a personality disorder sample: findings from the collaborative longitudinal personality disorders study. J Consult Clin Psychol (2005) 73(1):99-105. doi:10.1037/0022-006X.73.1.99

98. Diedrich A, Voderholzer U. Obsessive-compulsive personality disorder: a current review. Curr Psychiatry Rep (2015) 17(2):2. doi:10.1007/ s11920-014-0547-8

99. Grant JE, Mooney ME, Kushner MG. Prevalence, correlates, and comorbidity of DSM-IV obsessive-compulsive personality disorder: results from the national epidemiologic survey on alcohol and related conditions. J Psychiatr Res (2012) 46(4):469-75. doi:10.1016/j.jpsychires.2012.01.009

100. Ullrich S, Coid J. The age distribution of self-reported personality disorder traits in a household population. J Pers Disord (2009) 23(2):187-200. doi:10.1521/pedi.2009.23.2.187

101. Chen H, Cohen P, Crawford TN, Kasen S, Johnson JG, Berenson K. Relative impact of young adult personality disorders on subsequent quality of life: findings of a community-based longitudinal study. JPers Disord (2006) 20(5):510-23. doi:10.1521/pedi.2006.20.5.510

102. Skodol AE, Gunderson JG, McGlashan TH, Dyck IR, Stout RL, Bender DS, et al. Functional impairment in patients with schizotypal, borderline, avoidant, or obsessive-compulsive personality disorder. Am J Psychiatry (2002) 159(2):276-83. doi:10.1176/appi.ajp.159.2.276

103. Grilo CM, Skodol AE, Gunderson JG, Sanislow CA, Stout RL, Shea MT, et al. Longitudinal diagnostic efficiency of DSM-IV criteria for obsessivecompulsive personality disorder: a 2-year prospective study. Acta Psychiatr Scand (2004) 110(1):64-8. doi:10.1046/j.0001-690X.2003.00223.x

104. Conwell Y, Caine ED, Olsen K. Suicide and cancer in late life. Hosp Community Psychiatry (1990) 41(12):1334-9.

105. Horton-Deutsch SL, Clark DC, Farran CJ. Chronic dyspnea and suicide in elderly men. Hosp Community Psychiatry (1992) 43(12):1198-203.

106. Dombrovski AY, Szanto K, Siegle GJ, Wallace ML, Forman SD, Sahakian B, et al. Lethal forethought: delayed reward discounting differentiates high- and low-lethality suicide attempts in old age. Biol Psychiatry (2011) 70(2):138-44. doi:10.1016/j.biopsych.2010.12.025

107. Pinto A, Steinglass JE, Greene AL, Weber EU, Simpson HB. Capacity to delay reward differentiates obsessive-compulsive disorder and obsessivecompulsive personality disorder. Biol Psychiatry (2014) 75(8):653-9. doi:10.1016/j.biopsych.2013.09.007

108. Dirks BL. Repetition of parasuicide - ICD-10 personality disorders and adversity. Acta Psychiatr Scand (1998) 98(3):208-13. doi:10.1111/j. 1600-0447.1998.tb10068.x 
109. Raja M, Azzoni A. The impact of obsessive-compulsive personality disorder on the suicidal risk of patients with mood disorders. Psychopathology (2007) 40(3):184-90. doi:10.1159/000100366

110. Wilson RS, Krueger KR, Gu L, Bienias JL, Mendes de Leon CF, Evans DA. Neuroticism, extraversion, and mortality in a defined population of older persons. Psychosom Med (2005) 67(6):841-5. doi:10.1097/01.psy. 0000190615.20656 .83

111. Duberstein PR. Openness to experience and completed suicide across the second half of life. Int Psychogeriatr (1995) 7(2):183-98. doi:10.1017/ S1041610295001967

112. Costa PT, McCrae RR. Personality in adulthood: a six-year longitudinal study of self-reports and spouse ratings on the NEO personality inventory. J Pers Soc Psychol (1988) 54(5):853-63. doi:10.1037/0022-3514.54. 5.853

113. Samuel D, Widiger T. A meta-analytic review of the relationships between the five-factor model and DSM-IV-TR personality disorders: a facet level analysis. Clin Psychol Rev (2008) 28(8):1326-42. doi:10.1016/j.cpr.2008. 07.002

114. Wilson RS, BoylePA, Yu L, SegawaE, Sytsma J, Bennett DA.Conscientiousness, dementia related pathology, and trajectories of cognitive aging. Psychol Aging (2015) 30(1):74-82. doi:10.1037/pag0000013

115. Casey DA, Schrodt CJ. Axis II diagnoses in geriatric inpatients. J Geriatr Psychiatry Neurol (1989) 2(2):87-8.

116. Fogel BS, Westlake R. Personality disorder diagnoses and age in inpatients with major depression. J Clin Psychiatry (1990) 51(6):232-5.

117. Kelly TM, Mann JJ. Validity of DSM-III-R diagnosis by psychological autopsy: a comparison with clinician ante-mortem diagnosis. Acta Psychiatr Scand (1996) 94(5):337-43. doi:10.1111/j.1600-0447.1996.tb09869.x

118. Szanto K, Galfalvy H, Vanyukov PM, Keilp JG, Dombrovski AY. Pathways to late-life suicidal behavior: cluster analysis and predictive validation of suicidal behavior. J Clin Psychiatry (2017) 79(2):17m11611. doi:10.4088/ JCP. $17 \mathrm{~m} 11611$

119. Helmes E, Norton MC, Østbye T. Personality change in older adults with dementia: occurrence and association with severity of cognitive impairment. Adv Aging Res (2013) 2(1):27-36. doi:10.4236/aar.2013.21004

120. Balsis S, Carpenter BD, Storandt M. Personality change precedes clinical diagnosis of dementia of the Alzheimer type. J Gerontol B Psychol Sci Soc Sci (2005) 60(2):98-101. doi:10.1093/geronb/60.2.P98

121. Duchek JM, Balota DA, Storandt M, Larsen R. The power of personality in discriminating between healthy aging and early-stage Alzheimer's disease. J Gerontol B Psychol Sci Soc Sci (2007) 62(6):353-61. doi:10.1093/ geronb/62.6.P353

122. Duberstein PR, Chapman BP, Tindle HA, Sink KM, Bamonti P, Robbins J, et al. Personality and risk for Alzheimer's disease in adults 72 years of age and older: a 6-year follow-up. Psychol Aging (2011) 26(2):351-62. doi:10.1037/ a0023405

123. Bower JH, Grossardt BR, Maraganore DM, Ahlskog JE, Colligan RC, Geda YE, et al. Anxious personality predicts an increased risk of Parkinson's disease. Mov Disord (2010) 25(13):2105-13. doi:10.1002/mds.23230

124. Heberlein I, Ludin H-P, Scholz J, Vieregge P. Personality, depression, and premorbid lifestyle in twin pairs discordant for Parkinson's disease. J Neurol Neurosurg Psychiatry (1998) 64(2):262-6. doi:10.1136/jnnp.64.2.262
125. Glosser G, Clark C, Freundlich B, Kliner-Krenzel L, Flaherty P, Stern M. A controlled investigation of current and premorbid personality: characteristics of Parkinson's disease patients. Mov Disord (1995) 10(2):201-6. doi:10.1002/mds.870100211

126. Menza MA, Golbe LI, Cody RA, Forman NE. Dopamine-related personality traits in Parkinson's disease. Neurology (1993) 43(3 Pt 1):505-8. doi:10.1212/ WNL.43.3_Part_1.505

127. Voon V, Krack P, Lang AE, Lozano AM, Dujardin K, Schüpbach M, et al. A multicentre study on suicide outcomes following subthalamic stimulation for Parkinson's disease. Brain (2008) 131(10):2720. doi:10.1093/ brain/awn 214

128. Lee T, Lee HB, Ahn MH, Kim J, Kim MS, Chung SJ, et al. Increased suicide risk and clinical correlates of suicide among patients with Parkinson's disease. Parkinsonism Relat Disord (2016) 32:102-7. doi:10.1016/j.parkreldis. 2016.09.006

129. Lockwood KA, Alexopoulos GS, van Gorp WG. Executive dysfunction in geriatric depression. Am J Psychiatry (2002) 159(7):1119-26. doi:10.1176/ appi.ajp.159.7.1119

130. Alexopoulos GS, Kiosses DN, Heo M, Murphy CF, Shanmugham B, Gunning-Dixon F. Executive dysfunction and the course of geriatric depression. Biol Psychiatry (2005) 58(3):204-10. doi:10.1016/j.biopsych. 2005.04.024

131. Richard-Devantoy S, Berlim MT, Jollant F. A meta-analysis of neuropsychological markers of vulnerability to suicidal behavior in mood disorders. Psychol Med (2014) 44(8):1663-73. doi:10.1017/S0033291713002304

132. LeGris J, van Reekum R. The neuropsychological correlates of borderline personality disorder and suicidal behaviour. Can JPsychiatry (2006) 51(3):131-42. doi:10.1177/070674370605100303

133. Krakowski MI, Foxe J, de Sanctis P, Nolan K, Hoptman MJ, Shope C, et al. Aberrant response inhibition and task switching in psychopathic individuals. Psychiatry Res (2015) 229(3):1017-23. doi:10.1016/j.psychres. 2015.06.018

134. Fineberg NA, Day GA, de Koenigswarter N, Reghunandanan S, Kolli S, Jefferies-Sewell $\mathrm{K}$, et al. The neuropsychology of obsessive-compulsive personality disorder: a new analysis. CNS Spectr (2015) 20(5):490-9. doi:10.1017/S1092852914000662

135. Morey LC, Zanarini MC. Borderline personality: traits and disorder J Abnorm Psychol (2000) 109(4):733-7. doi:10.1037/0021-843X.109.4.733

136. Sharma L, Markon KE, Clark LA. Toward a theory of distinct types of "impulsive" behaviors: a meta-analysis of self-report and behavioral measures. Psychol Bull (2014) 140(2):374-408. doi:10.1037/a0034418

Conflict of Interest Statement: The authors declare that the research was conducted in the absence of any commercial or financial relationships that could be construed as a potential conflict of interest.

Copyright (c) 2018 Szücs, Szanto, Aubry and Dombrovski. This is an open-access article distributed under the terms of the Creative Commons Attribution License (CC $B Y)$. The use, distribution or reproduction in other forums is permitted, provided the original author(s) and the copyright owner are credited and that the original publication in this journal is cited, in accordance with accepted academic practice. No use, distribution or reproduction is permitted which does not comply with these terms. 